\title{
Dynamics of the Diurnal Warm Layer: Surface Jet, High-Frequency Internal Waves, and Mixing
}

\author{
Hemantha W. Wijesekera, David W. WAng, AND Ewa Jarosz \\ Naval Research Laboratory, Stennis Space Center, Mississippi
}

(Manuscript received 19 November 2019, in final form 12 May 2020)

\begin{abstract}
Evolution of a thermally stratified diurnal warm layer (DWL), including the formation and decay of a daytime surface-layer jet, high-frequency internal waves, and mixing were examined from observations collected during July 2016 , near $93.75^{\circ} \mathrm{W}, 28^{\circ} \mathrm{N}$, on the outer Louisiana-Texas continental shelf in the Gulf of Mexico, when the ocean surface was experiencing a weak sea breeze $\left(<5 \mathrm{~m} \mathrm{~s}^{-1}\right)$ and strong solar insolation. While winds and surface waves were weak, the DWL was formed with stratification strengthening and stability frequency reaching 14 cycles per hour at 2-m depth, while inhibiting turbulence below the DWL. A surface-intensified jet developed during afternoon hours. The jet, oriented to the right of the wind stress with a speed of about $10 \mathrm{~cm} \mathrm{~s}^{-1}$ at $2 \mathrm{~m}$, veered and decreased with depth. The magnitude of the diurnal jet was correlated with the heat content anomaly in the DWL. Internal waves with periods ranging from $5 \mathrm{~min}$ to $4 \mathrm{~h}$ were observed in the upper $4 \mathrm{~m}$. Temperature fluctuations were $\sim \pm 0.2^{\circ} \mathrm{C}$, and the corresponding vertical displacements varied from 0.5 to $1 \mathrm{~m}$. These fluctuations appeared during afternoon hours when the Richardson number dropped below the critical value of 0.25 followed by energetic mixing. The daytime jet and the high-frequency fluctuations disappeared a few hours after sunset. Internal waves were likely excited by Kelvin-Helmholtz instabilities and by surface wave and internal wave interactions. Mixing resulting from the dissipation of daytime internal waves is an important factor in regulating sea surface temperature in the DWL.
\end{abstract}

\section{Introduction}

Absorption of solar radiation generates a thermally stratified diurnal warm layer (DWL) extending a few meters below the surface. As a result, both sea surface temperature and upper-ocean heat content vary diurnally. The thickness of the DWL depends on the net surface heating, wind speed, and entrainment mixing at the base of the DWL (Price et al. 1986; Fairall et al. 1996; Kawai and Wada 2007; Soloviev and Lukas 2014). The depth of the heat penetration depends on the apparent optical properties of seawater (e.g., Jerlov 1976; Paulson and Simpson 1977). Recently, Moulin et al. (2018) reported the diurnal evolution of temperature, stratification, and turbulence in the diurnal warm layer during low to moderate winds and strong insolation in the equatorial Indian Ocean. The increase in near-surface stratification basically inhibits vertical mixing and entrainment that trap momentum imparted by surface

Corresponding author: H. W. Wijesekera, hemantha.wijesekera@ nrlssc.navy.mil winds and results in a diurnal jet in the DWL (e.g., Thorpe 1978; Sutherland et al. 2016; Moulin et al. 2018). The diurnal jet can be as large as $0.15-0.19 \mathrm{~m} \mathrm{~s}^{-1}$ at low winds (Kudryavtsev and Soloviev 1990; Sutherland et al. 2016). Kudryavtsev and Soloviev (1990) reported that the reduction of turbulent friction in the near-surface layer, as daytime heating increases, develops a "slippery near-surface layer" thus generating a current in the DWL. They further examined the physical processes by introducing a simple one-dimensional integral model which reproduces the diurnal variation of temperature and the associated diurnal jet. As the jet develops, it generates strong vertical shear to force shear-driven mixing through Kelvin-Helmholtz (KH) instabilities (Smyth et al. 2013; Sutherland et al. 2016). The diurnal cycle of near-surface shear layers are often observed near the equator (Cronin and Kessler 2009; Smyth et al. 2013; Callaghan et al. 2014; Wenegrat and McPhaden 2015). At the equator, steady trade winds, solar insolation, and entrainment fluxes are likely to control nearsurface velocities on the diurnal time scale. Away from the equator, however, such as in the northern Gulf of 
Mexico $\left(28^{\circ} \mathrm{N}\right)$, the Coriolis forcing can be another factor to consider.

During the past several decades, many small-scale observational studies have been focused on convective wind-wave-driven conditions and compared to nearsurface-layer processes during low winds and high solar insolation (e.g., many references can be found in Soloviev and Lukas 2014). Near-surface-layer processes have not been well described due to lack of observations which is partly due to technical difficulties of measuring the near-surface (upper $5 \mathrm{~m}$ ) turbulent-dissipation rates and velocity fields. This is still a major challenge, but now new instrumentation and platforms can help to overcome some of the difficulties encountered in the past.

Diurnal variabilities of sea surface temperature (SST) and heat content in the upper ocean have a major impact on surface heat fluxes and air-sea interactions on time scales larger than diurnal. Therefore, quantifying processes in the DWL are important for improving predictability of SST and for estimating accurate heat and momentum fluxes at the air-sea interface. To understand and quantify processes in the near-surface layer, the U.S. Naval Research Laboratory (NRL) conducted a field program titled "Turbulence in the Ocean Surface Boundary Layer (TGOM)." Two field programs, targeting summer (July 2016) and winter (February 2017) conditions, were conducted on the outer continental shelf in the Gulf of Mexico. Here, we examine the evolution and decay of the summertime diurnal warm layer using a subset of data collected in July 2016 when buoyancy forcing was dominated by solar insolation, while winds and surface waves were weak. Jarosz et al. (2020) address momentum fluxes in the mixed layer during wintertime high wind and wave conditions using observations collected in February 2017.

The paper is organized as follows. The instrumentation and mooring datasets are described in section 2. Currents, hydrographic fields, and turbulent kinetic energy (TKE) dissipation rates in the DWL are described in section 3. High-frequency variability and plausible generation mechanisms are discussed in sections 4 and 5 , respectively. Summary and conclusions are presented in section 6 .

\section{Instrumentation and measurements}

Three moorings with multiple sensors were deployed at five sites north of the Flower Garden Banks on the outer continental shelf of Louisiana-Texas (Fig. 1). The general location of the moorings is about $186 \mathrm{~km}$ from Galveston, Texas. MS1-MS4 mooring sites were at corners of a $10 \mathrm{~km} \times 10 \mathrm{~km}$ box, while the MS5 mooring site was approximately in the middle of the box. Water

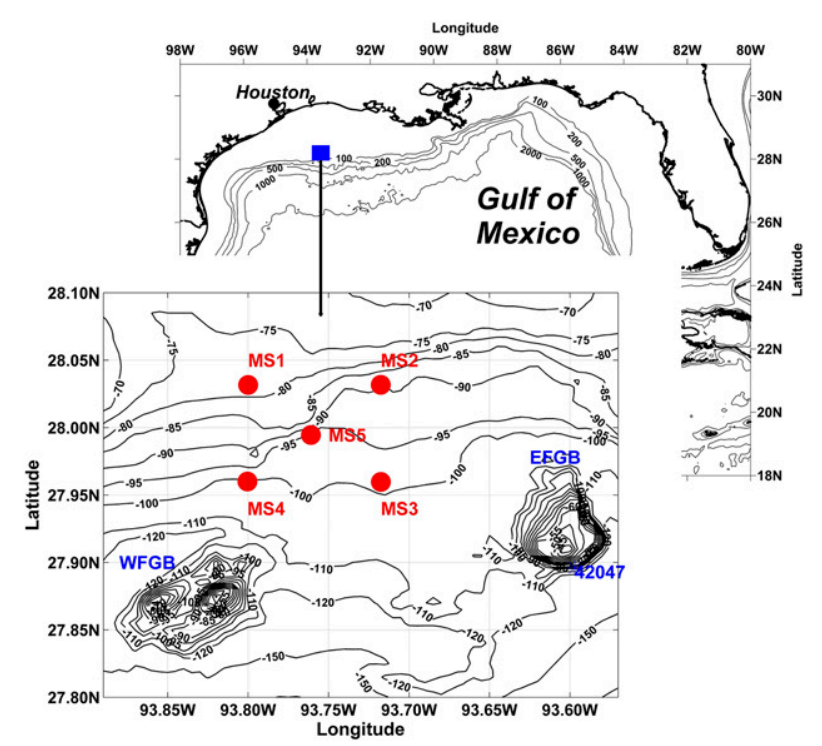

FIG. 1. Map of the bathymetry of the Gulf of Mexico. The blue square is the experimental site. The expanded section illustrates the locations of the East and West Flower Garden Banks (EFGB, WFGB), and the locations of the five mooring sites (MS1-MS5). The NDBC buoy 42047 is located at the southern edge of the EFGB. Black lines denote depth contours in meters.

depths were about 76, 89, 98, 100, and $95 \mathrm{~m}$ at MS1, MS2, MS3, MS4, and MS5, respectively. At all locations, hydrographic and current-velocity observations were recorded between 7 July and 19 July 2016. Each site consisted of three separate moorings that were located about 100 to $150 \mathrm{~m}$ apart. At MS1, MS2, MS3, and MS4, a trawlresistant bottom-mounted Barny (Perkins et al. 2000) and two line moorings were deployed. Each Barny was equipped with a $300-\mathrm{kHz}$ Teledyne RD Instruments (RDI) Sentinel V acoustic Doppler current profiler (ADCP). The ADCP heads were set about $0.5 \mathrm{~m}$ above the bottom and recorded current profiles at $1-\mathrm{m}$ vertical resolution, at a frequency of $2 \mathrm{~Hz}$. One of the line moorings also contained an ADCP deployed at about $10 \mathrm{~m}$ below the sea surface. These near-surface ADCPs were $1000-\mathrm{kHz}$ Teledyne RDI Sentinel V ADCPs at MS1 and MS3, and 500-kHz Teledyne RDI Sentinel V ADCPs at MS2 and MS4. They recorded current profiles at $2 \mathrm{~Hz}$ at $0.25-$ and $0.5-\mathrm{m}$ vertical resolutions for the 1000- and 500-kHz ADCPs, respectively. All ADCPs were also equipped with a wave package.

The second line mooring was a spar-buoy type, furnished with temperature $T$, conductivity $C$, and pressure $P$ sensors. Each spar buoy consisted of an aluminum cylinder, weighing about $35 \mathrm{~kg}$, and was $0.2 \mathrm{~m}$ in diameter and $6 \mathrm{~m}$ tall. Each mooring also contained an assortment of sensors mounted on the spar-buoy and along the wire beneath it. The instruments consisted of 
SBE37-MicroCats (manufactured by Sea Bird Electronics) for recording $T, C$, and $P$, Vemco temperature dataloggers, and Star ODDI conductivity, temperature, and depth (CTD) units.

TKE dissipation rates and high vertical resolution temperature and salinity (conductivity) profiles were collected from a SLOCUM glider with a mounted MicroRider microstructure package, and SBE3 and SBE4 sensors, respectively (e.g., Wolk et al. 2009). The MicroRider contained two shear probes, a thermistor, a tilt sensor, a pressure sensor, and an acceleration sensor, and sampled at a rate of $512 \mathrm{~Hz}$ whereas the SLOCUM glider sampled temperature and conductivity at a rate of $0.5 \mathrm{~Hz}$. A total of 700 up and down glider profiles were collected while the glider was operating along a $4 \mathrm{~km} \times$ $4 \mathrm{~km}$ box pattern encompassing the central mooring, MS5 (Fig. 1), where the water depth varied from 85 to $97 \mathrm{~m}$. The glider operated between the surface and $5 \mathrm{~m}$ above the bottom for four days beginning on 16 July.

The ADCP instruments returned high-quality time series of current velocities except for the near-bottom ADCP at MS1 that recorded only a partial record ending at 1010 UTC 6 July 2016, and the near-bottom ADCP at MS4 did not record any data. Moreover, highquality $T, C$, and $P$ time series were returned by many SBE37 sensors at MS1, MS2, MS3, and MS4.

Atmospheric observations such as air temperature, humidity, wind speed, wind direction, atmospheric pressure, and incoming solar irradiance were recorded by instruments installed on the $\mathrm{R} / \mathrm{V}$ Pelican. Unfortunately, the radiometer returned only a 3-day time series of solar irradiance (16-19 July). Therefore solar irradiance and net surface-heat fluxes were obtained from the Navy Global Environmental Model (NAVGEM) outputs (Hogan et al. 2014).

\section{Winds, solar heating, and currents in the diurnal warm layer}

\section{a. Winds, waves, and surface heat fluxes}

The solar insolation dominated surface heating during the experiment (Fig. 2a). The modeled net surface-heat flux indicates a steady diurnal cycle of daytime heating and nighttime cooling. The average daytime solar irradiance was about $400 \mathrm{~W} \mathrm{~m}^{-2}$, and nighttime cooling was about $160 \mathrm{~W} \mathrm{~m}^{-2}$. Surface winds were moderate during the first seven days of the experiment; winds consisted of a mean wind blowing from south at about $5 \mathrm{~m} \mathrm{~s}^{-1}$ and a diurnal sea breeze less than $2.5 \mathrm{~m} \mathrm{~s}^{-1}$ (Fig. 2b). Surface winds at $4 \mathrm{~m}$ height above the sea surface were collected every $30 \mathrm{~min}$ from the National Data Buoy Center (NDBC) buoy 42047, located near the East Flower Garden Bank (Fig. 1) (https://www.ndbc.noaa.
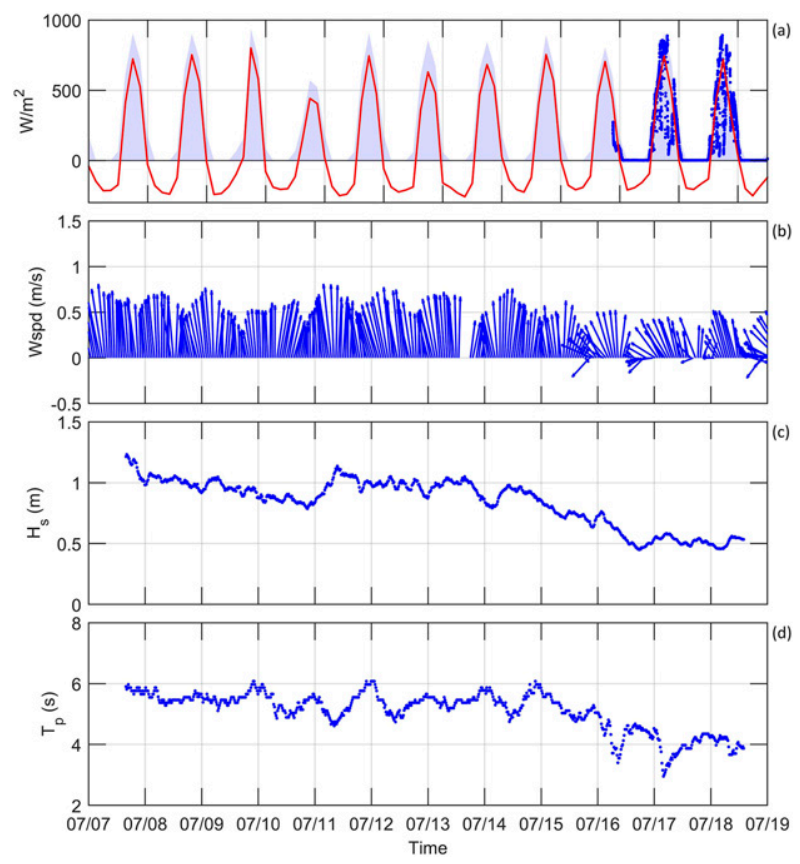

FIG. 2. Time series of (a) net heat flux (red), modeled shortwave flux (light-blue filled) and observed shortwave flux (blue dots), (b) wind vectors from the NDBC buoy 42047 , where the wind sensor was located at $4 \mathrm{~m}$ above the sea level, (c) significant wave height $H_{s}$, and (d) dominant wave period $T_{p}$ from the ADCP wave measurements at MS2. Time series of net heat flux and shortwave flux are from NAVEGEM. Time is in UTC.

gov/station_page.php?station =42047). Surface wave height $H_{s}$ and period $T_{p}$ were about $1 \mathrm{~m}$, and $6 \mathrm{~s}$, respectively (Figs. 2c,d). Surface wave information for every 20-min period was obtained from the ADCP wave-tracking system at MS2. During 15-19 July, weather conditions became calm as southerly winds subsided. Winds were dominated by the sea-breeze cycle with magnitudes of about $2.5 \mathrm{~m} \mathrm{~s}^{-1}$. Several days prior to the end of the observational period, surface waves became smaller, where $H_{s}$ was less than $0.5 \mathrm{~m}$ and $T_{p}$ was about $4 \mathrm{~s}$ (Figs. 2c,d). For the deep water, surface wave wavelengths $L$ at the beginning and end of the observational period are limited to about 54 and $25 \mathrm{~m}$, respectively, where $L=(g / 2 \pi) T_{p}^{2}$ and $g$ is the gravitational acceleration.

\section{b. Currents and hydrography}

The $U$ and $V$ velocities were dominated by nearinertial oscillations with periods close to $24 \mathrm{~h}$ (Fig. 3). Velocity components in the full water column were constructed by combining velocities in the upper $8 \mathrm{~m}$ from a string-mounted upward-looking 500-kHz ADCP at $10 \mathrm{~m}$ with velocities below $8 \mathrm{~m}$ from a bottom-mounted upward-looking 300-kHz ADCP at MS2. The vertical bin size was $0.5 \mathrm{~m}$. Velocities exhibit a two-layer vertical 

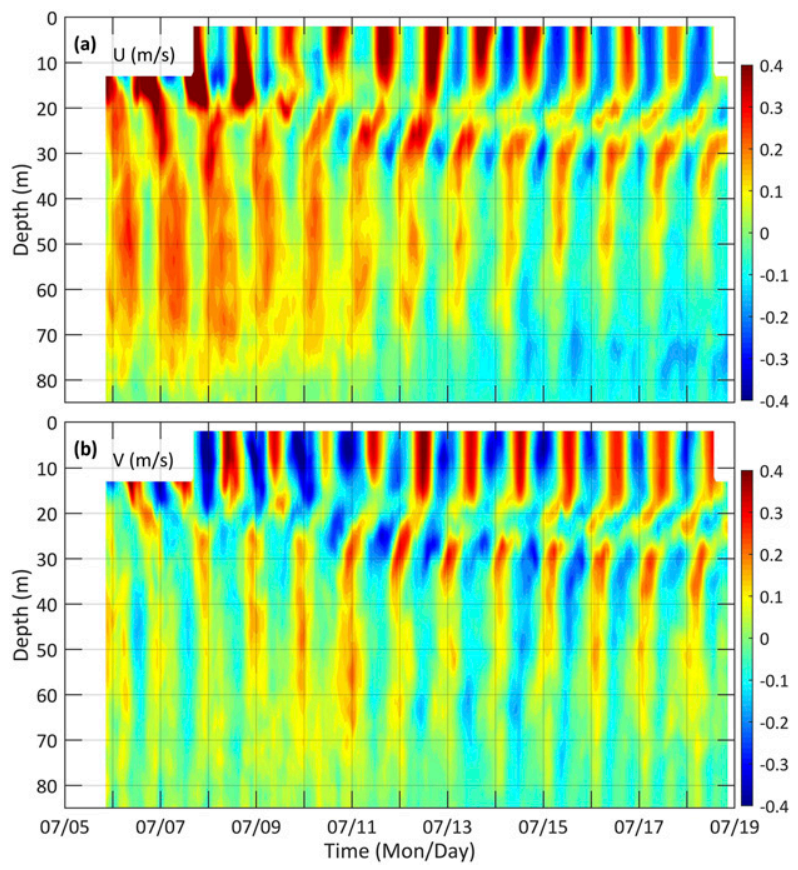

FIG. 3. Hourly averaged (a) zonal velocity $U$ and (b) meridional velocity $V\left(\mathrm{~m} \mathrm{~s}^{-1}\right)$ at MS2.

structure reflecting first-mode near-inertial waves. The upper layer was $\sim 20 \mathrm{~m}$ thick while the lower layer extended from $20 \mathrm{~m}$ above the bottom to the bottom. In general, currents were largest in the upper layer, and decayed with depth. However, $U$ and $V$ were also strong in the lower layer, especially during the early part of the record. Vertical shears of $U$ and $V$ were largest at the layer interface. The layered velocity structure was consistent with the vertical distribution of potential temperature $\theta$ and salinity $S$ in the water column (Fig. 4).

Figure 4 shows a few selected glider ascending profiles of $\theta$ and $S$ on 16 July representing daytime and nighttime conditions. A sharp pycnocline near $15-25 \mathrm{~m}$ in depth separated a thin top layer of warm, low-salinity riverine water from a thick layer of highsalinity Gulf of Mexico water. Temperature and salinity profiles further illustrate a bottom boundary with a thickness of $15-20 \mathrm{~m}$ (Fig. 4), where bottom currents were $10-15 \mathrm{~cm} \mathrm{~s}^{-1}$ (Fig. 3). The mixed layer deepened to about $15-20 \mathrm{~m}$ at night. The near-surface layer restratified and formed a DWL in the upper $8 \mathrm{~m}$ as daytime heating continued. The temperature difference between day and night in the upper $1 \mathrm{~m}$ was as large as $0.8^{\circ} \mathrm{C}$ (Fig. 4a), but such day and night differences in near-surface salinity were not found near the surface (Fig. 4b).

Moored observations provide high-resolution time series of $\theta$ and $S$ at sensor locations, while glider observations provide high-resolution vertical profiles of $\theta$ and $S$
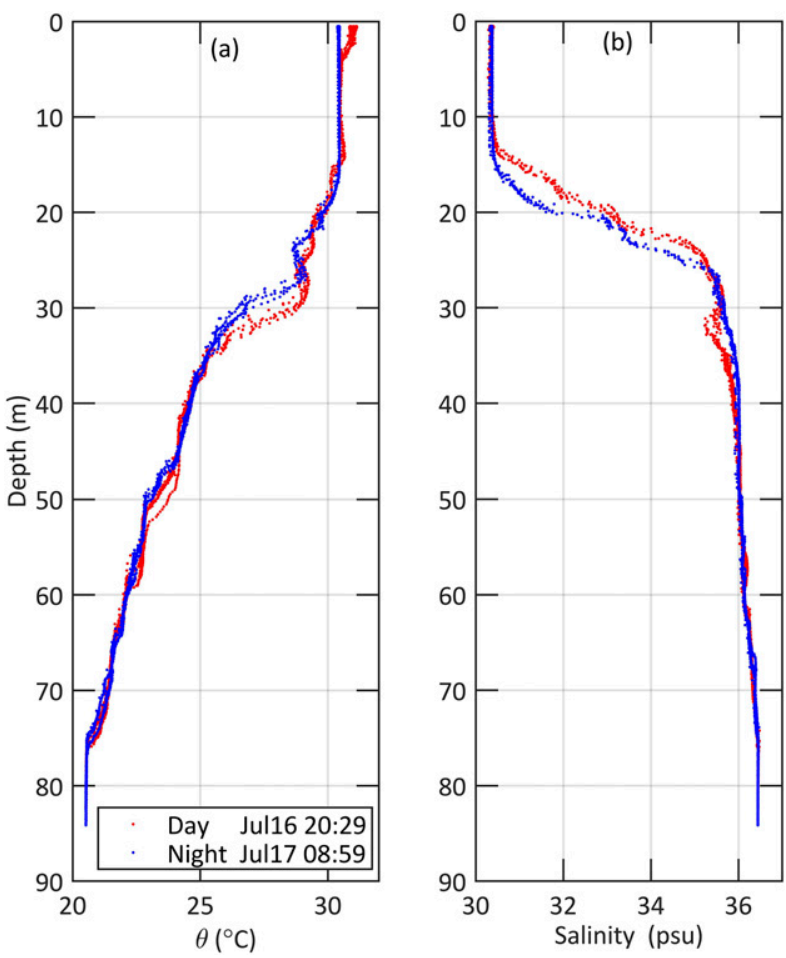

FIG. 4. Selected daytime (red) and nighttime (blue) profiles of (a) temperature and (b) salinity from the SLOCUM glider. Daytime and nighttime profiles were collected during 2030-2130 UTC 16 Jul and 0859-0959 UTC 17 Jul, respectively.

with limited lateral/temporal resolution. Therefore, we combined both moored and glider observations to capture space-time variability in the DWL. When winds and waves were weak during 15-19 July, temperature and density formed a diurnal cycle in the upper $8 \mathrm{~m}$. A seabreeze cycle with amplitudes of about $2.5 \mathrm{~m} \mathrm{~s}^{-1}$ dominated the wind field. Figure 5 shows $\theta$, potential density $\sigma_{\theta}$, and $S$ in the upper $10 \mathrm{~m}$ at MS2 during 15-19 July. Time-depth sections of temperature, salinity, and density were based on SBE37 Microcats on the spar-buoy mooring line. Each spar buoy contained six to seven SBE37 sensors at depths between 1.7 and $10 \mathrm{~m}$. The glider observations (Fig. 6) show that the daytime $\theta$ and $\sigma_{\theta}$ were stratified near the surface. The daytime temperature differences between the surface and $2 \mathrm{~m}$ were about $0.5^{\circ} \mathrm{C}$, which are similar to the temperature differences between 2 and $8 \mathrm{~m}$. In general, a rapid increase in temperature started in the middle of each day when the incoming solar heating was strongest, although the magnitude of daytime temperature differences in the upper $2 \mathrm{~m}$ varied during the observational period (Fig. 6b). The near-surface warm layer deepened to about $5 \mathrm{~m}$ as surface heating continued, and stopped abruptly when daytime heating ceased. Figures $5 \mathrm{c}$ and $6 c$ show a decrease in near-surface $\sigma_{\theta}$ in the DWL. 


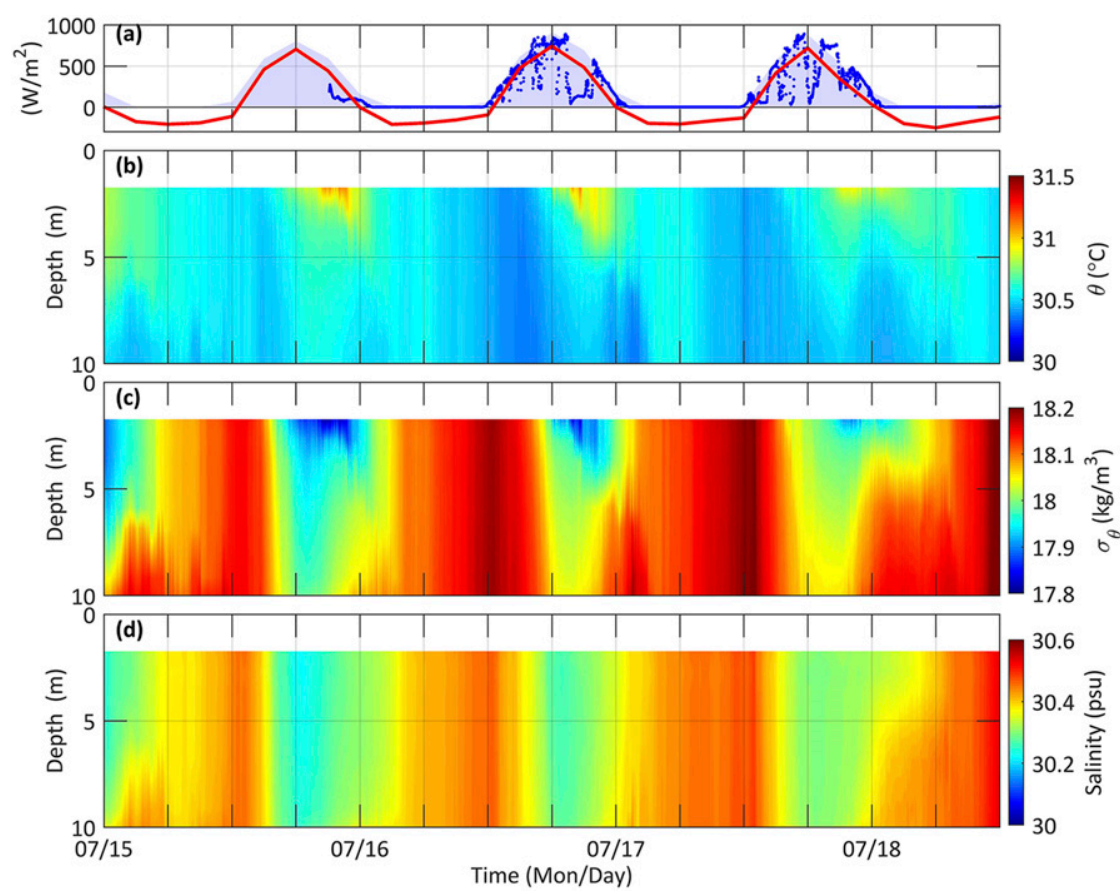

FIG. 5. Time series of (a) net heat flux (red), modeled shortwave flux (light-blue filled), and observed shortwave flux (blue dots). Near-surface time-depth section of (b) temperature, (c) potential density, and (d) salinity at MS2.

Here, $\sigma_{\theta}$ was mainly controlled by the temperature. However, near-surface salinity was not coupled with the solar cycle, although it varied with near-inertial waves in the entire water column (Figs. $5 \mathrm{~d}$ and $6 \mathrm{~d}$ ).

\section{c. Diurnal surface jet}

To obtain diurnal velocity components near the surface, background near-inertial waves must be removed, which is not a trivial task because the period of near-inertial waves is close to a day and the diurnal tidal period. Here, we adapted a method for defining near-surface velocity as suggested by Price et al. (1986) and Sutherland et al. (2016). Temperature and velocity differences relative to the reference level can be written as

$$
\begin{aligned}
& \Delta T(z, t)=\theta(z, t)-\theta\left(z_{r}, t\right), \\
& \Delta U(z, t)=U(z, t)-U\left(z_{r}, t\right), \\
& \Delta V(z, t)=V(z, t)-V\left(z_{r}, t\right),
\end{aligned}
$$

and the heat content anomaly $\Delta H$ in the DWL was calculated by integrating the temperature fluctuations defined in (1) between the reference depth $z_{r}$ and the surface, where

$$
\Delta H=\int_{-z_{r}}^{0} \rho_{\theta} C_{p} \Delta T(z, t) d z
$$

$C_{p}$ is the specific heat of seawater, and $z_{r}$ represents the depth of a layer below the diurnal layer but above the pycnocline to avoid pycnocline variability. The depthaveraged temperature difference over $z_{r}$ is expressed as

$$
\overline{\Delta T}=\Delta H /\left(\rho_{\theta} C_{p} z_{r}\right) .
$$

Here background near-inertial waves were removed by subtracting currents and temperatures at $7.8-\mathrm{m}$ depth $\left(z_{r}=7.8 \mathrm{~m}\right)$ from the velocity and temperature records since near-inertial waves were relatively uniform in the upper layer. Note that this procedure allows identification of the diurnal surface jet, but may not necessarily provide the absolute magnitude of the surface jet. The increase in near-surface stratification led to a formation of the diurnal jet as momentum imparted by the wind was trapped in the DWL. Note that the formation of the diurnal jet was registered at all four mooring sites, and only observations of the jet at MS2 are presented (Fig. 7c). Largest velocities occurred during late afternoon hours, when vertical stratification became strongest (Figs. $5 b, c$ and $6 b, c)$. The near-surface velocities (Fig. 7c) were directed to the right of the rotating wind direction (Fig. 7b). The surface current veered with depth, representing the Ekman-type spiral (Fig. 7c). Two selected, hourly-averaged profiles of velocity anomalies in the upper $8 \mathrm{~m}$ further illustrate the veering of currents with depth (Figs. 7d,e). The polar 

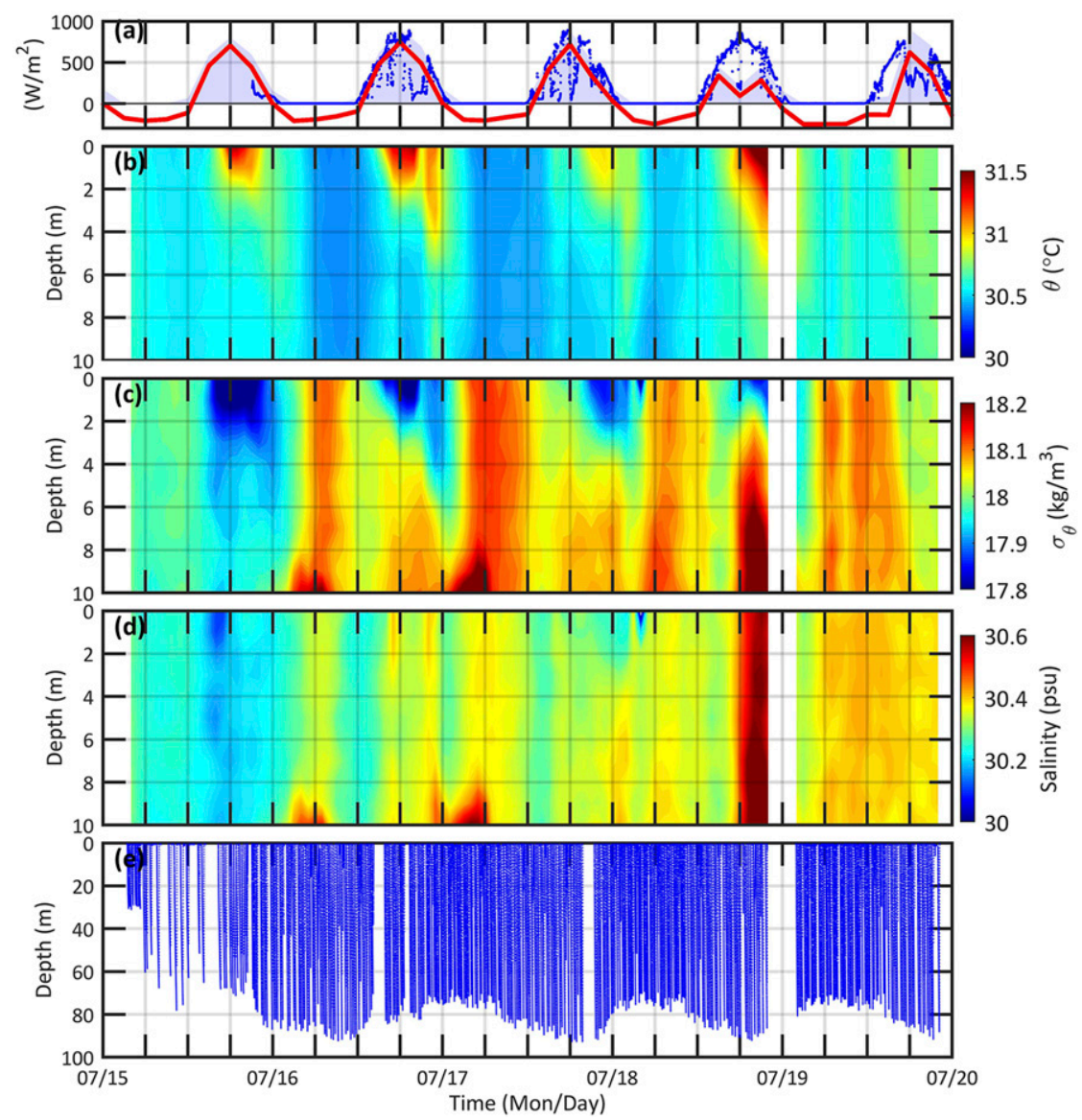

FIG. 6. Time series of (a) net heat flux (red), modeled shortwave flux (light-blue filled), and observed shortwave flux (blue dots). Time-depth sections of (b) potential temperature $\left({ }^{\circ} \mathrm{C}\right)$, (c) potential density $\left(\mathrm{kg} \mathrm{m}^{-3}\right)$, (d) salinity (psu) in the upper $10 \mathrm{~m}$ from the SLOCUM glider, and (e) glider profile extent in the upper $100 \mathrm{~m}$. The glider was operated along the $4 \mathrm{~km} \times 4 \mathrm{~km}$ box pattern inside the mooring array.

histogram of angular difference $\Delta \theta$ between wind direction and near-surface current at $1.8 \mathrm{~m}$ indicates that, in most occasions, the near-surface flow was to the right of the wind direction (Fig. 7f), although $\Delta \theta$ was not always consistent with the Ekman theoretical estimate of $45^{\circ}$. These observations suggest that the Coriolis effect becomes an important factor for this time-varying surfaceintensified current.

The depth-averaged flow $(\overline{\Delta U}, \overline{\Delta V})$ in the DWL can be approximated as

$$
\begin{aligned}
& \frac{\partial \overline{\Delta U}}{\partial t}-f \overline{\Delta V}=\frac{1}{\rho} \frac{\tau_{x}}{h}, \\
& \frac{\partial \overline{\Delta V}}{\partial t}+f \overline{\Delta U}=\frac{1}{\rho} \frac{\tau_{y}}{h},
\end{aligned}
$$

where $\tau_{x}$ and $\tau_{y}$ are east-west and north-south wind stress components, respectively, $\rho$ is the near-surface density, and $h$ is a depth where turbulent stresses can be neglected. The steady-state momentum balance between the wind stress divergence and Coriolis acceleration produces a velocity of about $5 \mathrm{~cm} \mathrm{~s}^{-1}$ for $\tau_{x}=\tau_{y}=$ $0.025 \mathrm{~N} \mathrm{~m}^{-2}, h=7.8 \mathrm{~m}$, and $f=7.25 \times 10^{-5} \mathrm{~s}^{-1}$. The estimated Ekman-type flow is similar in order of magnitude with the observed depth-averaged velocity (see Fig. 12c) indicating that Coriolis forcing is an important factor in the governing physics.

\section{d. Turbulent mixing}

Time series of surface net heat flux, solar radiation, and time-depth sections of $\theta$, buoyancy frequency squared $\left(N^{2}\right)$, squared shear of horizontal currents $\left(\mathrm{sh}^{2}\right)$, and $\mathrm{sh}^{2}-4 N^{2}$ where $N^{2}=-\left(g / \rho_{\theta}\right)\left(\partial \sigma_{\theta} / \partial z\right), \rho_{\theta}=\sigma_{\theta}+1000$, and $\operatorname{sh}^{2}=(\partial U / \partial z)^{2}+(\partial V / \partial z)^{2}$ (Fig. 8) display the diurnal cycle in the upper $10 \mathrm{~m}$ at MS2. Diurnal cycles of $N^{2}, \mathrm{sh}^{2}$, and $\mathrm{sh}^{2}-4 N^{2}$ (Figs. 8b-d), closely follow the solar insolation (Fig. 8a). $\theta, N^{2}$, and $\mathrm{sh}^{2}$ deepened with time but 

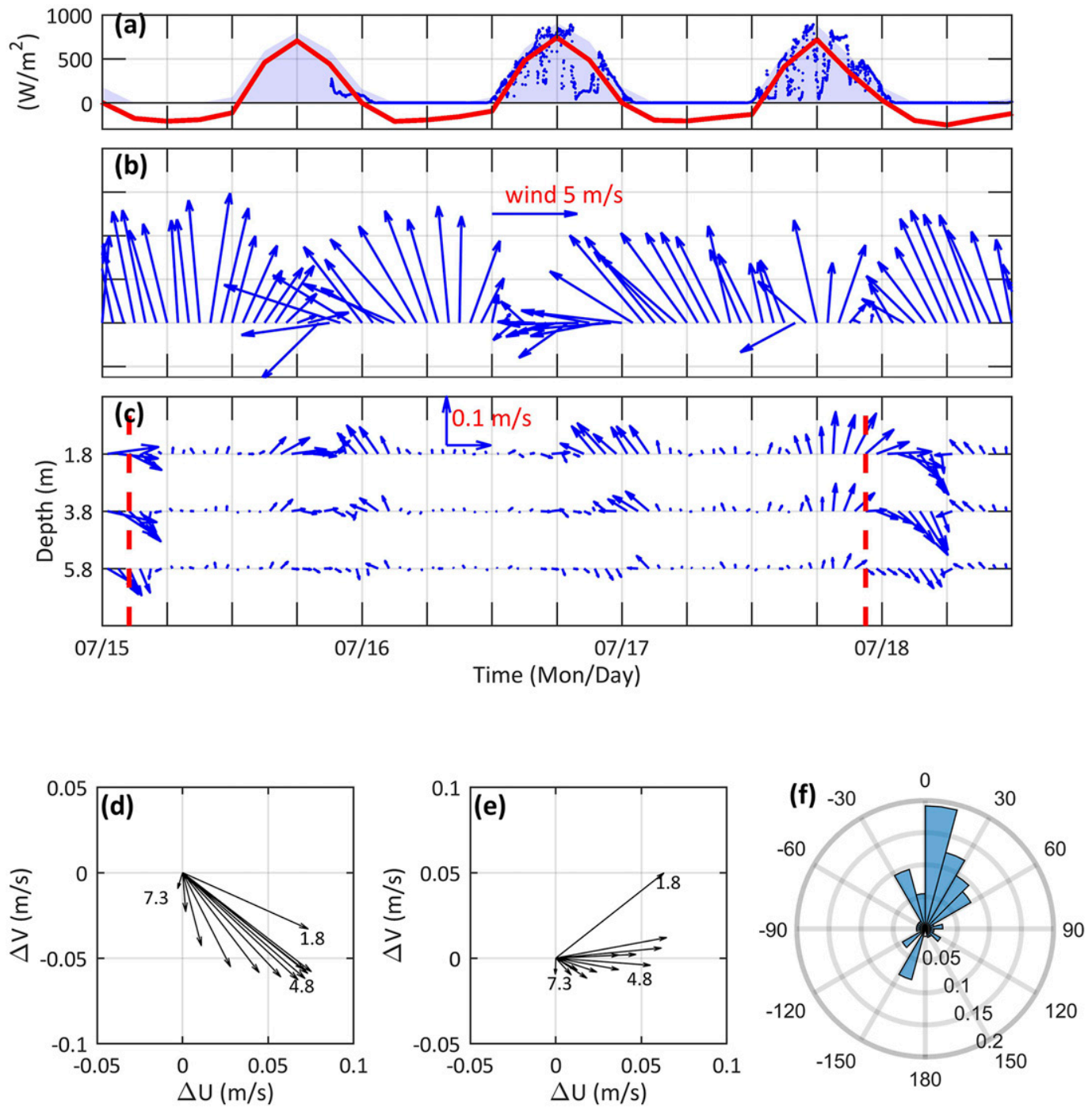

FIG. 7. Time series of (a) net heat flux (red), modeled shortwave flux (light-blue filled), and observed shortwave flux (blue dots); (b) wind vectors; and (c) near-surface diurnal jet at depths of 1.8, 3.8, and 5.8 $\mathrm{m}$ at MS2. Red dashed lines denote the time of two selected velocity profiles plotted as current spirals in (d) and (e). (d),(e) Hourly averaged current profiles in the upper $7.8 \mathrm{~m}$ at $0230 \mathrm{UTC} 15 \mathrm{Jul}$ and $2230 \mathrm{UTC} 17 \mathrm{Jul}$, respectively. The depth profiles started from $1.8 \mathrm{~m}$ down to $7.8 \mathrm{~m}$ with a $0.5-\mathrm{m}$ interval. Depths of $1.8,4.8$, and $7.3 \mathrm{~m}$ are marked in (d) and (e). The current at $7.8 \mathrm{~m}$ is the reference speed corresponding to $\Delta U=0$, and $\Delta V=0$. (f) Polar histogram of the probability distribution of the angular difference $\Delta \theta$ of current direction at $1.8 \mathrm{~m}$ and wind direction for wind speeds larger than $2 \mathrm{~m} \mathrm{~s}^{-1}$. The positive $\Delta \theta$ indicates that the surface current is to the right of the vector wind.

stopped deepening when solar heating ended. Flow becomes unstable to KH instabilities when $\mathrm{sh}^{2}-4 N^{2}>0$, i.e., the Richardson number, $\mathrm{Ri}=N^{2} / \mathrm{sh}^{2}<0.25$. Such regions can be found in afternoon to evening hours but limited to the upper 3-4 m (Fig. 8d), which in turn implies that the shear-driven mixing dominates generation of the TKE dissipation rate prior to the buoyancy-driven mixing associated with nighttime cooling.

TKE dissipation rates and turbulent eddy diffusivities were examined from microstructure profiles collected by a MicroRider package mounted on a SLOCUM glider platform. The glider provided ascending and descending profiles of hydrographic and turbulence fields. Pitch angle of ascending and descending glider paths are typically $14^{\circ}-22^{\circ}$ from horizontal and along path speeds vary from 0.3 to $0.4 \mathrm{~m} \mathrm{~s}^{-1}$ (Wolk et al. 2009). Here a thruster attached to the tail end of the glider was used to maintain ascending speeds and near vertical profiles comparable to the standard operation of the vertical microstructure profiler. The separation times between two consecutive upward profiles varied from 20 to $30 \mathrm{~min}$. Here we limited our dissipation estimates to ascending profiles in order to 

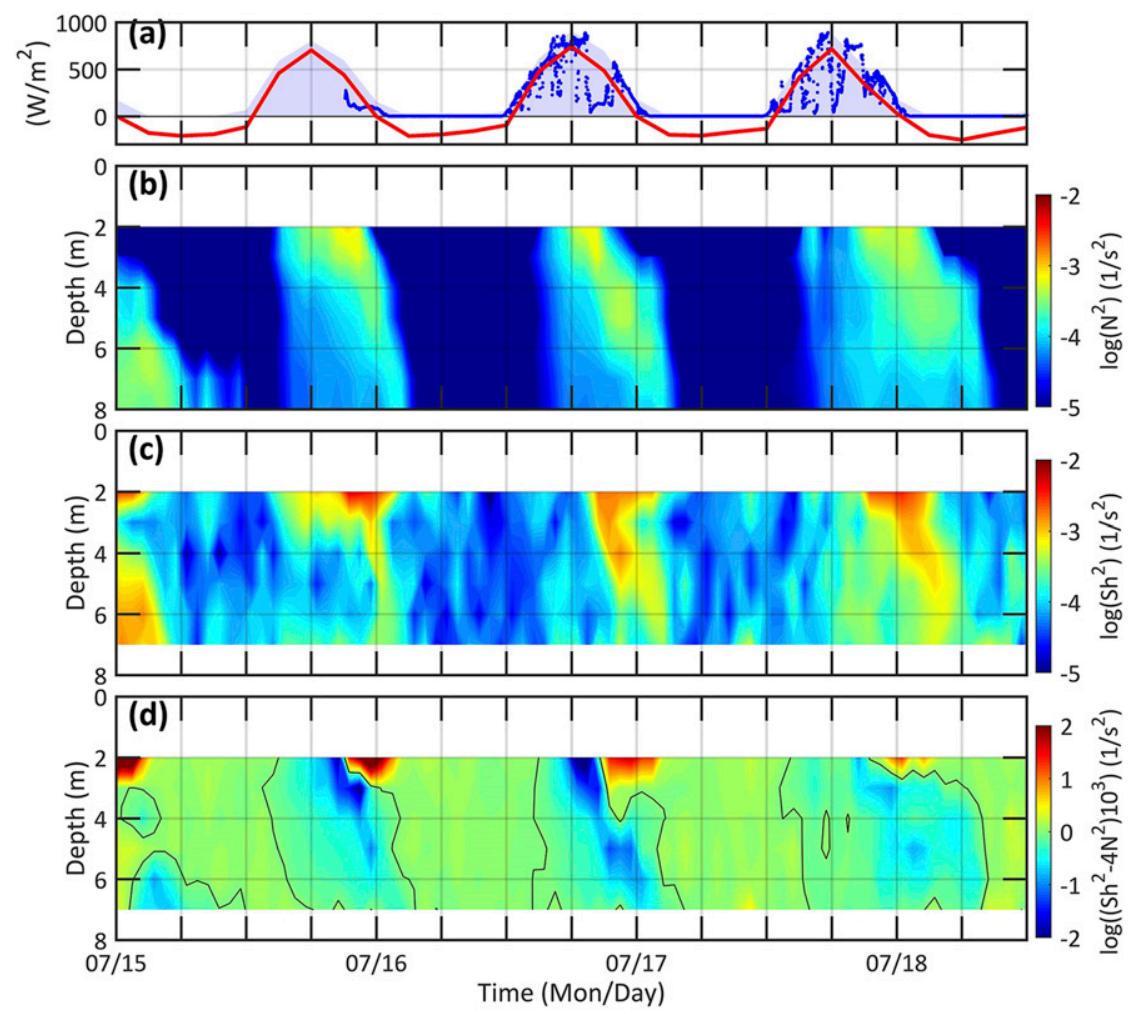

FIG. 8. Time series of (a) net heat flux (red), modeled shortwave flux (light-blue filled) and observed shortwave flux (blue dots). Time-depth sections of $\log _{10}$ values of (b) buoyancy frequency squared $N^{2}$, (c) shear squared $\mathrm{sh}^{2}$, and (d) $\left(\mathrm{sh}^{2}-4 N^{2}\right) \times 10^{3}$; black contours in (d) denote $\mathrm{sh}^{2}-4 N^{2}=0$, which represents $\mathrm{Ri}=0.25$ at MS2.

have clean microscale-velocity-shear signals near the surface. The pitch angle $\delta$ and the rising speed of the glider were $50^{\circ}-80^{\circ}$ counterclockwise from the horizontal and $0.6-0.8 \mathrm{~m} \mathrm{~s}^{-1}$, respectively, when the thruster was on (Figs. 9a,b). The speed along the glider path $U_{G}$ for a given $\delta$ was approximated as

$$
U_{G}=(d P / d t) / \sin (\delta),
$$

where $P$ is the pressure. The incident water velocity, an important factor for estimating TKE dissipation rates, is not always equal to $U_{G}$, due to a discrepancy between the glider pitch angle and the attack angle of the incident water velocity, which in turn causes uncertainties in the estimate of the TKE dissipation rate. Note that the TKE dissipation rate is inversely proportional to the fourth power of the incident water velocity. Merckelbach et al. (2019) reported that the dissipation rate can be within a factor from 1.1 to 1.2 for the standard SLOCUM glider operations with $\delta=28^{\circ}-32^{\circ}$. Here $\delta$ varied from $50^{\circ}$ to $80^{\circ}$ (Fig. 9b) when the thruster was on, and therefore we reevaluated the attack angle using a steady-state glider model as discussed in Merckelbach et al. (2010), where the angle of attack [Eq. (12) in Merckelbach et al. 2010] is expressed as

$$
\alpha=\frac{C_{D 0}+\left(C_{D 1 w+} C_{D 1 h}\right) \alpha^{2}}{\left(a_{w}+a_{h}\right) \tan (\delta+\alpha)},
$$

where $\alpha$ is measured from the glider's principal axis, and $\delta$ is the pitch angle from the horizontal axis (Fig. 1 in Merckelbach et al. 2010); $C_{D 0}$ is the parasite drag coefficient, $C_{D 1 h}$ is the drag coefficient for the hull and $C_{D 1 w}$ is the drag coefficient for the wings; $a_{h}$ and $a_{w}$ are liftslope coefficients for the hull and wings, respectively (for details see Merckelbach et al. 2010; Williams et al. 2007). Here we solved (6) iteratively for different values of $\delta$ while using coefficients specified by Merckelbach et al. (2010): $C_{D 0}=0.1, C_{D 1 h}=2.1 \mathrm{rad}^{-2}, C_{D 1 w}=$ $0.78 \mathrm{rad}^{-2}, a_{h}=3.7 \mathrm{rad}^{-1}$, and $a_{w}=2.4 \mathrm{rad}^{-1}$ for a SLOCUM- 1000 glider. For $\delta=20^{\circ}, 40^{\circ}, 60^{\circ}$, and $80^{\circ}, \alpha$ is about $2.4^{\circ}, 1.5^{\circ}, 0.5^{\circ}$ and $0.2^{\circ}$, respectively. The deviation of the attack angle from the pitch angle is less than $1^{\circ}$ for $\delta$ varying from $50^{\circ}$ to $80^{\circ}$, and therefore the approximation of the incident water velocity as $U_{G}$ [Eq. (5)] is an adequate estimate for small $\alpha$ values.

The TKE dissipation rate $\varepsilon$ was estimated by evaluating the turbulent-shear variance from a spectrum computed over 512 data points for 2-s data records, 

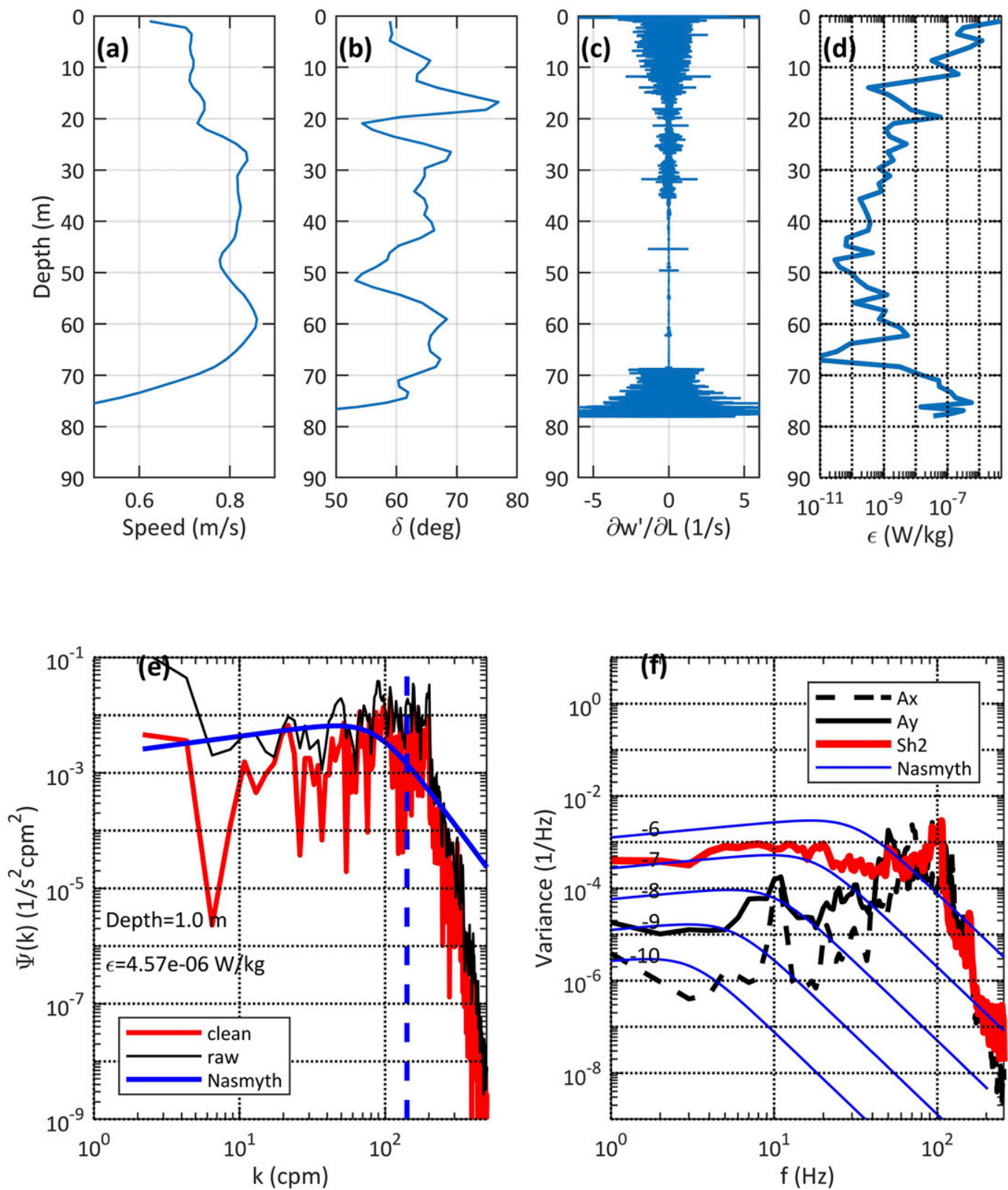

FIG. 9. Measuring TKE dissipation rates from ascending profiles of the SLOCUM glider. (a) Speed of the glider along the glider path. (b) $\delta$ is the pitch angle measured from the horizontal axis. (c) Raw velocity shear fluctuations along the glider path. (d) Estimated TKE dissipation rate $\varepsilon$. (e) Examples of raw wavenumber spectrum of shear (black), and spectrum of despiked and cleaned shear (red) along with the fitted Nasmyth spectra (blue solid blue line) at $1 \mathrm{~m}$ below the surface. The blue dashed line represents the high-wavenumber cutoff for the dissipation estimate. (f) Frequency spectra of acceleration components (Ax and Ay) along with shear for 1-10-m depth range. Solid blue lines are the Nasmyth spectra for dissipation estimates ranging from $10^{-10}$ to $10^{-6} \mathrm{~W} \mathrm{~kg}^{-1}$.

by following the software developed by Douglas and Lueck (2015), and is given by

$$
\varepsilon=\frac{15}{2} \nu\left\langle\left(\frac{\partial w^{\prime}}{\partial l}\right)^{2}\right\rangle,
$$

where $\left\langle\left(\partial w^{\prime} / \partial l\right)^{2}\right\rangle$ is the variance of turbulent shear along the glider path, and $\nu$ is the kinematic viscosity. Turbulent shear variance was computed from a given shear spectrum (Figs. 9e,f) by integrating from a low wavenumber corresponding to a 1 -s data record to a maximum wavenumber determined by the noise level 


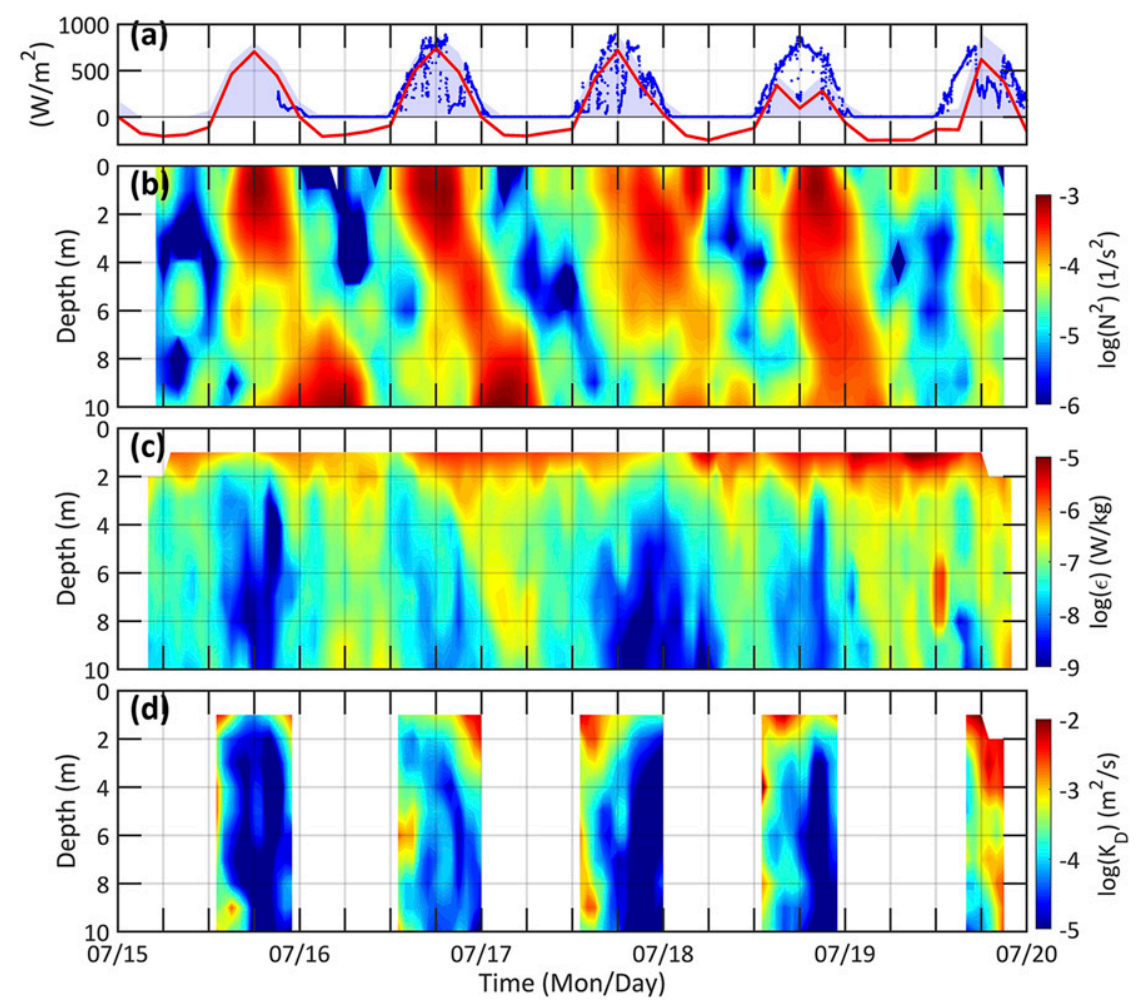

FIG. 10. Time series of (a) net heat flux (red), modeled shortwave flux (light-blue filled) and observed shortwave flux (blue dots). Time-depth series of $\log _{10}$ (b) buoyancy frequency squared, (c) TKE dissipation rate $\varepsilon$, and (d) turbulent eddy diffusivity $K_{D}$ when the surface heat flux was positive (daytime heating).

(e.g., Douglas and Lueck 2015; Lueck 2016). Note that, based on Taylor's frozen turbulence hypothesis, wavenumber (cycles per meter) $=[$ frequency $(\mathrm{Hz})] /[$ speed of the glider $\left.\left(\mathrm{m} \mathrm{s}^{-1}\right)\right]$. Estimates of $\varepsilon$ are based on the assumption that turbulent velocity fluctuations are isotropic, and therefore evaluating one component of shear is sufficient to compute the TKE dissipation rate (e.g., Tennekes and Lumley 1972). The thruster and perhaps the CTD pump generated a broadband noise at the $45-100-\mathrm{Hz}$ frequency band, but did not generate adverse effects on the TKE dissipation estimate (Fig. 9f). The noise level of the TKE dissipation rate is about $10^{-10} \mathrm{~W} \mathrm{~kg}^{-1}$. A total of 350 profiles of $\varepsilon$ between 0.5 and $80 \mathrm{~m}$ were constructed, and hourly averaged $\varepsilon$ and $\sigma_{\theta}$ were used for estimating $N^{2}$ and turbulent eddy diffusivity $K_{D}$, where

$$
K_{D}=\Gamma \varepsilon / N^{2},
$$

and the mixing efficiency $\Gamma$ is 0.2 (Gregg et al. 2018). Note that the estimates of $K_{D}$ were limited to the daytime heating since (8) is not valid for nighttime buoyancy-driven turbulence. Figure 10 shows time-depth sections of $\varepsilon, N^{2}$, and $K_{D}$ in the upper $10 \mathrm{~m}$. The $N^{2}$ values in the upper $2 \mathrm{~m}$ were as large as $10^{-3} \mathrm{~s}^{-2}$ when the solar insolation was strongest (Fig. 10b), and gradually increased as the DWL deepened. High values of $\varepsilon\left(\sim 10^{-6} \mathrm{~W} \mathrm{~kg}^{-1}\right)$ were found in the upper $2 \mathrm{~m}$, but $\varepsilon$ was inhibited below the DWL as thermal stratification developed (Figs. 10b,c). Underneath the DWL, $\varepsilon$ dropped below $10^{-8} \mathrm{~W} \mathrm{~kg}^{-1}$, and $K_{D}$ became on the order of $10^{-5} \mathrm{~m}^{2} \mathrm{~s}^{-1}$. However, during late afternoon hours both $\varepsilon$ and $K_{D}$ within the DWL exceeded $10^{-7} \mathrm{~W} \mathrm{~kg}^{-1}$ and $10^{-3} \mathrm{~m}^{2} \mathrm{~s}^{-1}$ (Figs. 10c,d), respectively. These changes were observed when Ri dropped below critical due to an increase in velocity shear (Fig. 8d). The nighttime cooling destroyed the strongly stratified DWL, and thus $\varepsilon$ penetrated to deeper depths (Fig. 10c).

Combined moored and glider observations (Fig. 11) further illustrate the diurnal cycle of temperature, nearsurface jet at multiple depths, shear and stratification, Richardson number averaged between 2 and $5 \mathrm{~m}$, and TKE dissipation rate at multiple depths for 16 July 2016. The temperature at $2 \mathrm{~m}$ peaked at about 1400 local time with a temperature difference between day and night of about $0.6^{\circ} \mathrm{C}$ (Fig. 11b). It appeared that the temperature within about $1 \mathrm{~m}$ from the surface was extremely sensitive to changes in solar insolation, as can be seen in the rapid decrease in near-surface temperature due to the sudden drop in solar irradiance (Figs. 11a,b). The temperature 

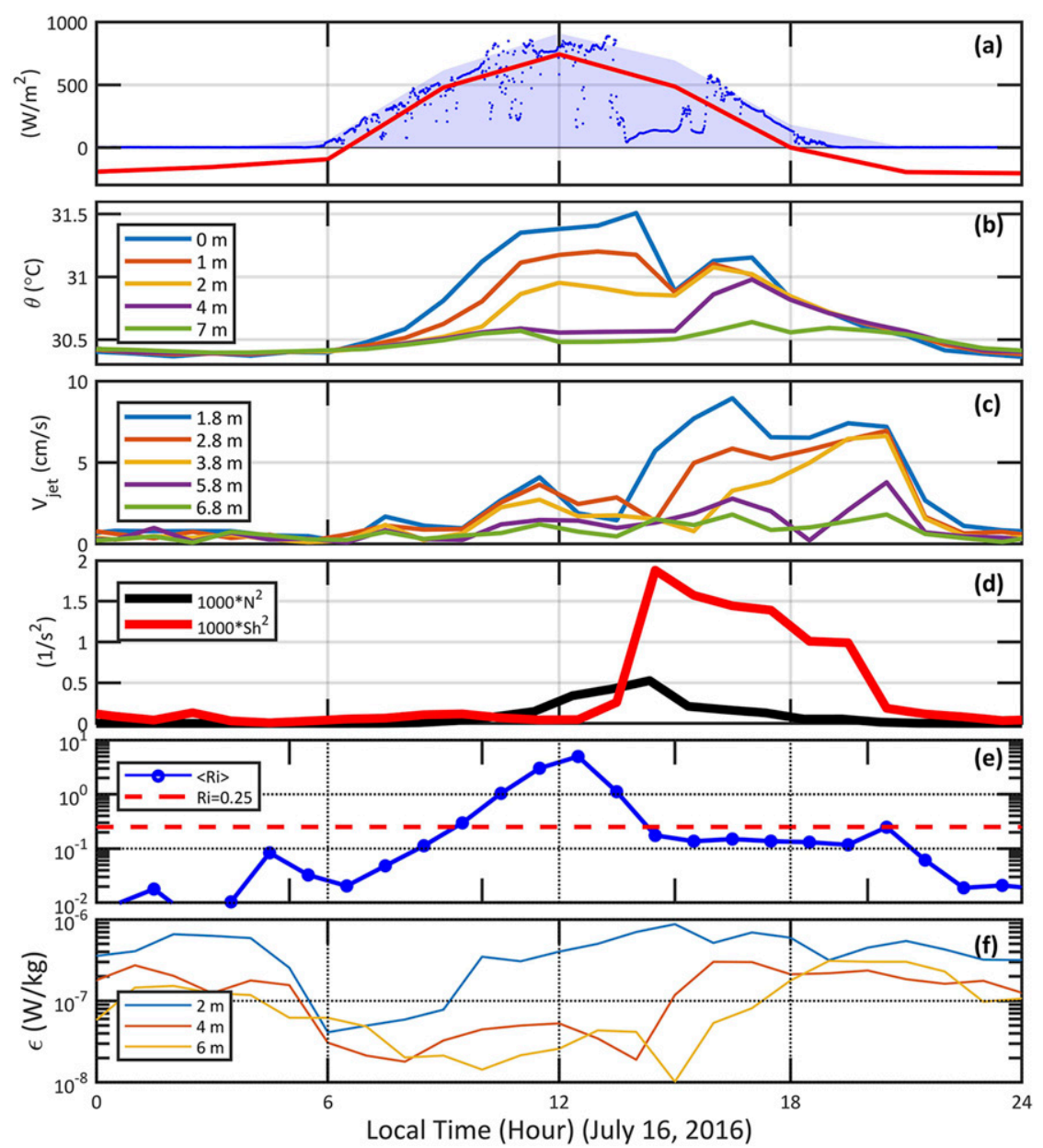

FIG. 11. Time series of (a) net heat flux (red), modeled shortwave flux (light-blue filled), and observed shortwave flux (blue dots) on 16 Jul 2016. (b) Temperature from the glider at the surface and 1, 2, 3, 4, and $7 \mathrm{~m}$. (c) Daytime jet speeds at 1.8, 2.8, 3.8, 5.8, and 6.8 $\mathrm{m}$ at MS2. (d) Buoyancy frequency squared (black) and shear squared averaged between 1.8 and $3.8 \mathrm{~m}$. (e) Richardson number (Ri) estimated from $N^{2}$ and $\mathrm{sh}^{2}$ shown in (d). (f) Hourly averaged TKE dissipation rates at 2,4 , and $6 \mathrm{~m}$. The red dashed line in (e) denotes $\mathrm{Ri}=0.25$.

difference increased at deeper depths as heating continued and $N^{2}$ reached $\sim 5 \times 10^{-4} \mathrm{~s}^{-2}$ (Fig. 11d). Formation of the diurnal surface jet at $2 \mathrm{~m}$ lagged the maximum temperature and maximum stratification by approximately $2 \mathrm{~h}$ (Figs. 11b,c). Note that the magnitude of the surface jet is $V_{\text {jet }}=\left(\Delta U^{2}+\Delta V^{2}\right)^{1 / 2}$. The surface jet generated vertical shear and drove the Richardson number below 0.25 (Fig. 11e), which in turn satisfied the necessary condition for the $\mathrm{KH}$ instability. The strong thermal stratification prevented the penetration of turbulent mixing below the DWL especially during morning hours (Fig. 11f), but $\varepsilon$ increased in the near-surface layer during late afternoon hours. The increase of $\varepsilon$ in the DWL coincided with the decrease in $\mathrm{Ri}$ below 0.25 , suggesting a generation of shear-driven turbulence. The downward turbulent heat fluxes $-\rho C_{p} K_{D} d \theta / d z$ associated with the shear-driven mixing events at the base of the DWL were about 200 $400 \mathrm{~W} \mathrm{~m}^{-2}$, for $K_{D} \sim 10^{-3} \mathrm{~m}^{2} \mathrm{~s}^{-1}, d \theta / d z \sim 0.05-0.1 \mathrm{C}^{\circ} \mathrm{m}^{-1}$, $C_{p}=4000 \mathrm{~J} \mathrm{~kg}^{-1} \mathrm{~K}^{-1}$, and $\rho=1020 \mathrm{~kg} \mathrm{~m}^{-3}$ (Figs. 10 and 11). Total heat transport, say within $4 \mathrm{~h}$, can be as large as $3-6 \mathrm{MJ} \mathrm{m}^{-2}$, which is a significant fraction of the daytime heat buildup in the DWL (for heat content anomaly see below). During nighttime $\varepsilon$ increased, and penetrated to deeper depths, and the mixed layer deepened as surface cooling continued. As discussed below, the KH instability is likely a plausible mechanism for generating high-frequency temperature fluctuations in the DWL, which eventually lead to enhance mixing.

\section{e. Heat content anomaly and diurnal jet}

The heat content anomaly $\Delta H$ [Eq. (3a)] at MS1MS3 (Fig. 12b) was calculated by integrating diurnal 

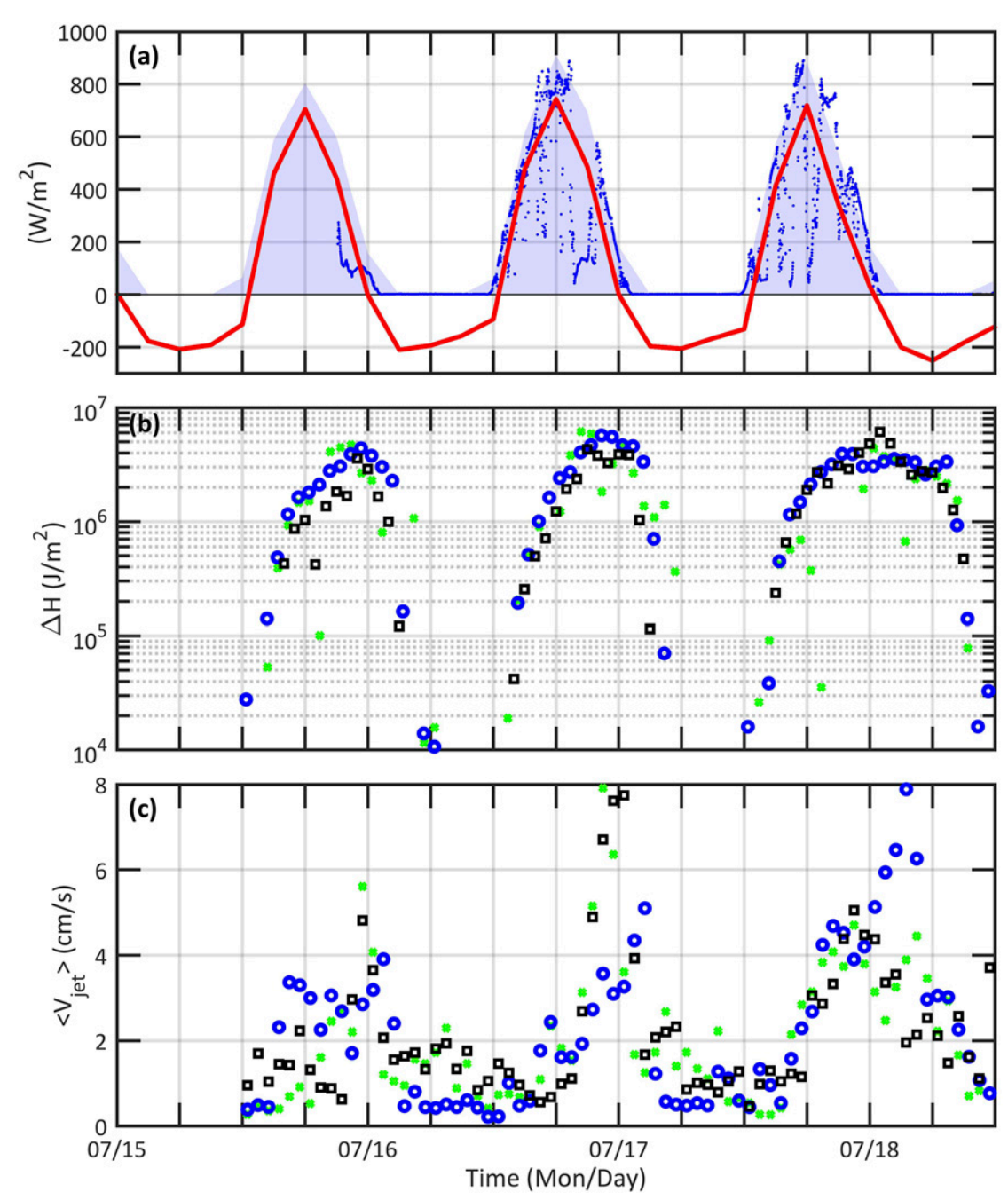

FIG. 12. Time series of (a) net heat flux (red), modeled shortwave flux (light-blue filled), and observed shortwave flux (blue dots); (b) heat content $\Delta H$; and (c) depth-averaged surface jet at MS1 (green crosses), MS2 (blue circles), and MS3 (black squares).

temperature fluctuations defined in (1) from the surface to the reference depth $z_{r}$, where $z_{r}=7.8 \mathrm{~m}$. The largest $\Delta H, \sim 5 \mathrm{MJ} \mathrm{m}^{-2}$, occurred a few hours after the maximum solar insolation, and disappeared after sunset (Fig. 12b). However, on 18 July, $\Delta H$ remained high after midnight, indicating that the nighttime cooling was not sufficient to break down the stratification immediately. The depth-averaged surface jet followed the heat content anomaly well without apparent time lags (Fig. 12c), unlike with the nearsurface temperature (Fig. 11b), where there is time lag between the surface jet and temperature anomaly.

We find a tight relationship between the heat content anomaly and the magnitude of the diurnal jet, although this relationship is nonlinear (Fig. 13). The jet increased rapidly as $\Delta H$ increased above $1 \mathrm{MJ} \mathrm{m}^{-2}$. Here the magnitude of velocity was compared with the heat content anomaly since the velocity of the jet rotated with depth. Since the averaged-temperature difference $\overline{\Delta T}$ is directly proportional to $\Delta H$ [Eq. (3b)], the findings in Figs. 12 and 13 are also qualitatively related to findings of Kudryavtsev and Soloviev (1990), who reported that the temperature difference and the velocity jet in the DWL are connected through the bulk Richardson number. Measuring near-surface velocities is a difficult task. The relationship between $\Delta H$ and $V_{\text {jet }}$ can be used to estimate the near-surface velocity contributed by the daytime heating.

\section{High-frequency variability}

High-frequency temperature fluctuations were found in the diurnal warm layer (Fig. 14), where temperature fluctuations $T^{\prime}$ were examined from 30 -s sampled temperature 


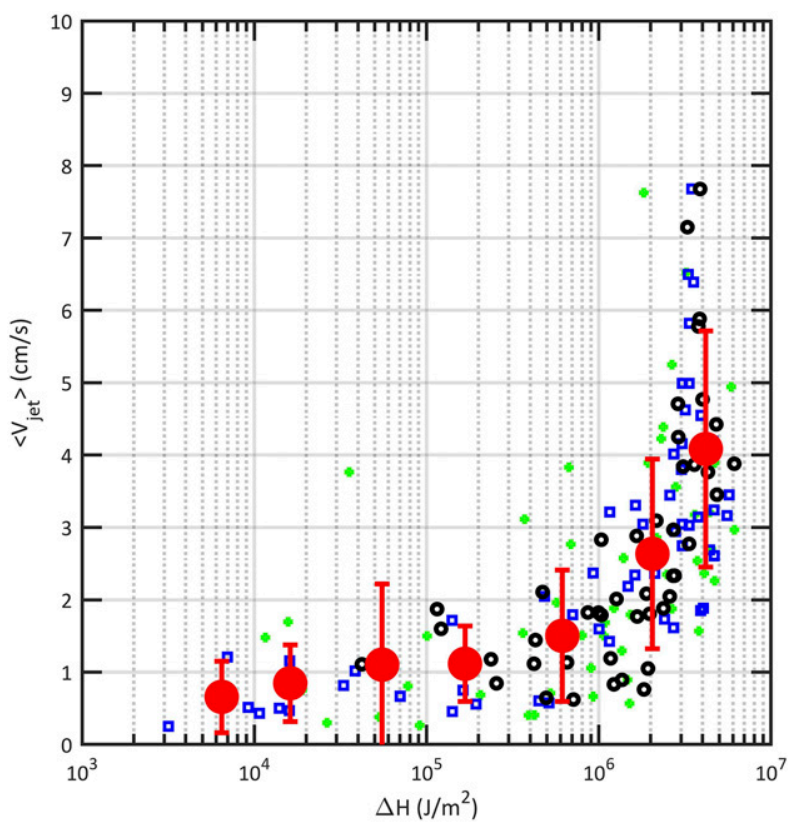

FIG. 13. The integrated heat content in the DWL vs the depthaveraged diurnal jet speed for MS1-MS3 shown in Figs. 12b and 12c. Red bullets with error bars are the bin-averaged velocity jet and standard error estimates, respectively.

observations after applying a bandpass filter for periods between 5 and $240 \mathrm{~min}$. The 5 -min cutoff period removes surface waves, and the 240-min cutoff period captures high-frequency variability. Movements of the spar buoy can create unnatural temperature fluctuations in the presence of strong vertical stratification. As discussed in section 2, time series of temperature at different depth levels were measured by the SBE37 Microcats mounted on the spar buoy, which extended to about $2.4 \mathrm{~m}$ above the surface. Under low-wind conditions $\left(<5 \mathrm{~m} \mathrm{~s}^{-1}\right)$, vertical displacements of the spar buoy were less than $3 \mathrm{~cm}$ for periods of oscillations less than $4 \mathrm{~h}$. Therefore, temperature fluctuations due to the vertical motion of sensors attached to the spar buoy for a background stratification of about $0.2^{\circ} \mathrm{Cm}^{-1}$ (Figs. 14 and 15 ) were less than $0.008^{\circ} \mathrm{C}$, which are significantly smaller than the observed high-frequency temperature fluctuations (Figs. 14b and 15b). The wavelet spectrum of temperature fluctuations at $1.8 \mathrm{~m}$ (Figs. 14b,c) illustrates the existence of the diurnal cycle of high-frequency temperature variance for periods ranging from $4 \mathrm{~h}$ to $5 \mathrm{~min}$ (Fig. 14c). Similar temperature fluctuations at multiple depths at MS3 (e.g., 2.1, 3.1, and $4.1 \mathrm{~m}$ ) (Fig. 15b) were registered at all four moorings.

Vertical displacements $\eta_{T}$ associated with bandpassed (5-240 $\mathrm{min}$ ) temperature fluctuations $T^{\prime}$ were computed by following $\eta_{T}=T^{\prime} / \partial T / \partial z$, where $\partial T / \partial z$ is the 4-h low-passed vertical temperature gradient. The vertical displacemnt $\eta_{T}$ was about $\pm 0.5 \mathrm{~m}$ at $2.1 \mathrm{~m}$ and was about $\pm 1.8 \mathrm{~m}$ at $4.1 \mathrm{~m}$ for mooring sites MS1-MS3. Figure 15 illustrates $T^{\prime}$ and $\eta_{T}$ at MS3. These are internal wave fluctuations in the DWL extending to the buoyancy frequency. Perturbation potential energy $(\mathrm{PE})$ can be as large as $(0.5-5) \times$ $10^{-4} \mathrm{~m}^{2} \mathrm{~s}^{-2}$ at MS3 (Fig. 15d). Here PE was based on local buoyancy frequency and vertical displacement, where $\mathrm{PE}=0.5 N^{2} \eta_{T}^{2}$. We can expect that the kinetic energy of the wave field would be a similar order of magnitude as PE.

The mean vertical profile of internal wave potential energy, in the upper $10 \mathrm{~m}$ was constructed by averaging PE estimates from three mooring sites for 16-19 July. Figure 16 shows buoyancy frequency, internal wave rms displacements, and PE for three mooring sites, and TKE dissipation rates within the mooring array averaged over time when internal waves were active in the DWL. On average, the rms wave displacement was about $0.5 \mathrm{~m}$, the $\mathrm{PE}$ was about (1-2) $\times 10^{-4} \mathrm{~m}^{2} \mathrm{~s}^{-2}$, and the corresponding TKE dissipation rates in the 2-5-m depth range were about $5 \times 10^{-8}-5 \times 10^{-7} \mathrm{~W} \mathrm{~kg}^{-1}$. The dissipation of $\mathrm{PE}$ produces vertical mixing through production of the turbulent buoyancy flux. In the presence of strong stratification, as found in the DWL, the buoyancy flux associated with shear-driven turbulence is $\sim \Gamma \varepsilon$. By considering the balance between buoyancy production and dissipation of $\mathrm{PE}$, we can approximate the time scale of the $\mathrm{PE}$ dissipation as $\mathrm{PE} / \Gamma \varepsilon$. For $\mathrm{PE}=$ $(1-2) \times 10^{-4} \mathrm{~m}^{2} \mathrm{~s}^{-2}, \varepsilon=5 \times 10^{-8}-5 \times 10^{-7} \mathrm{~W} \mathrm{~kg}^{-1}$, and $\Gamma=0.2$, the time scale of internal wave energy dissipation is about $0.5-3 \mathrm{~h}$. These estimates suggest that internal wave fluctuations in the DWL decayed rapidly.

\section{Generation of internal waves}

\section{a. Kelvin-Helmholtz instability}

Internal waves can be generated through $\mathrm{KH}$ instabilities in a region where $\mathrm{Ri}<0.25$ (Figs. $8 \mathrm{~d}$ and $11 \mathrm{e}$ ). There are numerous studies of $\mathrm{KH}$ instabilities using theoretical, laboratory, and numerical methods. Hazel (1972) and Thorpe (1971) examined instability of parallel, stratified shear flows by solving the Taylor-Goldstein equation. They derived the most unstable horizontal wavenumbers as a function of Richardson number for specified velocity and density profiles. Here we approximate the near-surface velocity profile, $u(\zeta)=U_{0} \tanh (\zeta)$, where $\zeta=z / h, z$ is the vertical coordinate, $h$ is the vertical length scale, and $U_{0}$ is the velocity scale (see Fig. 2 in Hazel 1972). For a $\tanh (\zeta)$ velocity profile with Ri numbers varying from 0.1 to 0.2 (Figs. $8 \mathrm{~d}$ and 11e), the nondimensional horizontal wavenumber $\alpha$ of the fastest growing disturbance is 0.4 (Table 1 in Thorpe 1971). For $h=7.8 \mathrm{~m}$, the wavelength of the fastest growing mode is 

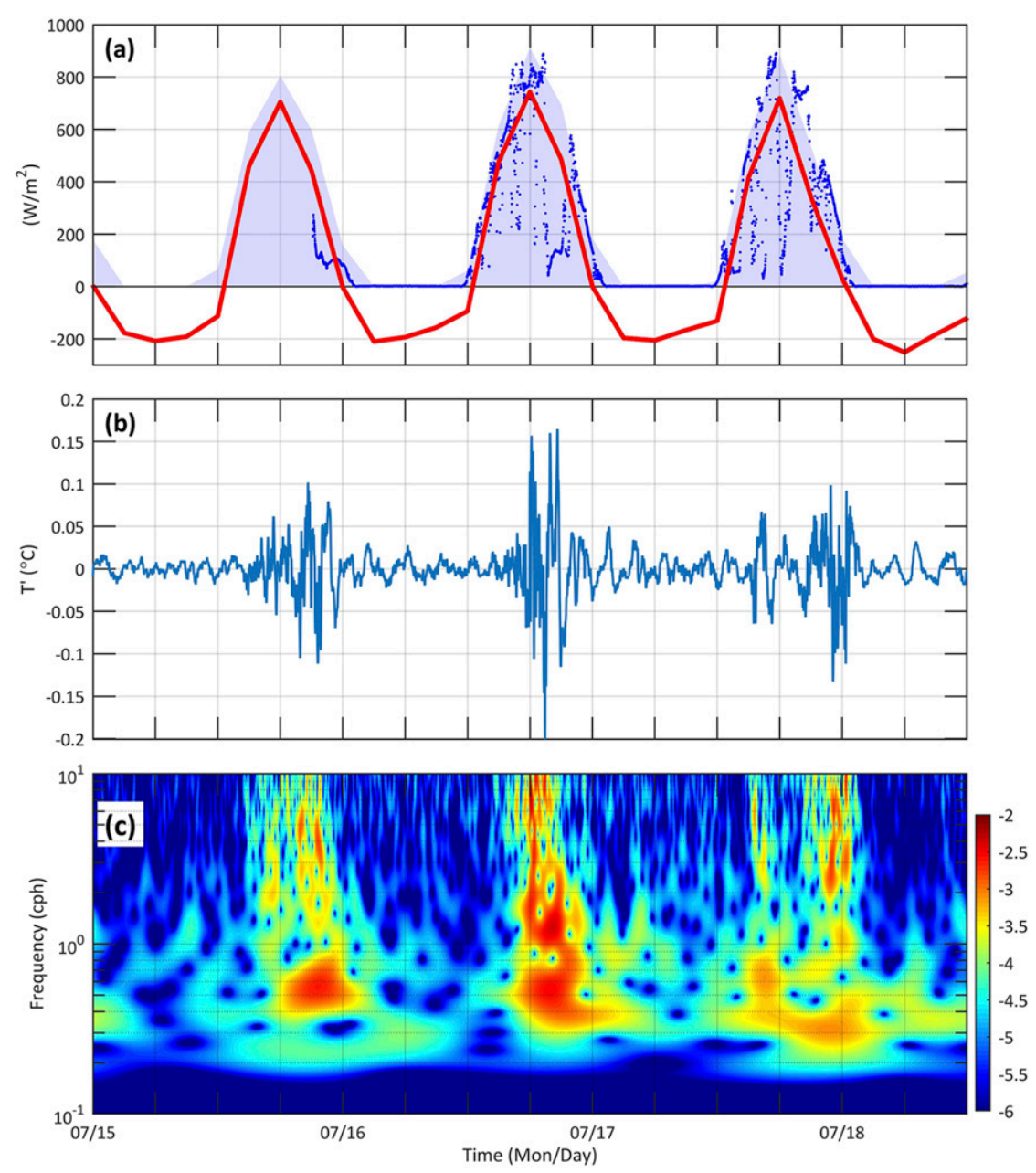

FIG. 14. Time series of (a) net heat flux (red), modeled shortwave flux (light-blue filled), and observed shortwave flux (blue dots), (b) near-surface bandpassed temperature fluctuations at MS2 (depth $=1.7 \mathrm{~m})$, and (c) the corresponding wavelet spectrum, $\log [\Phi(t, \omega)]$.

about $2 \pi h / \alpha \sim 100 \mathrm{~m}$. We can also consider a diurnal warm layer as a vortex sheet with thickness of about $h$ or $7.8 \mathrm{~m}$. Linear theory suggests that waves (disturbances) with wavelengths of $\lambda$ become unstable when $\lambda \leq$ $\pi \rho_{0} \Delta u^{2} / g \Delta \rho$ (Hazel 1972), where $\Delta u$ and $\Delta \rho$ are velocity and density differences between the two layers, and $g=9.81 \mathrm{~m} \mathrm{~s}^{-2}$. For $\Delta u=0.1 \mathrm{~m} \mathrm{~s}^{-1}$ and $\Delta \rho=0.06 \mathrm{~kg} \mathrm{~m}^{-3}$ between 2 and $7 \mathrm{~m}$ (Figs. 8 and 11), $\lambda$ is about $60 \mathrm{~m}$, which is smaller than the estimate based on a continuously stratified solution for a $\tanh (\zeta)$ velocity profile. This study indicates that horizontal wavelengths of observed temperature fluctuations are $\sim 60-100 \mathrm{~m}$.

\section{b. Interaction between a pair of surface waves and an internal wave}

Energy transfer through resonant interaction between two surface waves and one internal wave is a plausible mechanism within the highly stratified DWL. Internal waves can be excited or the existing wave disturbances (such as generated by KH instabilities) can be amplified by gaining energy from the surface wave field through these interactions. Several studies examined resonant triad interactions between two surface waves and one internal wave analytically for two-layer, three-layer, and continuously stratified flows (e.g., Ball 1964; Thorpe 1966; Kenyon 1968; Brekhovskikh et al. 1972; Thorpe 1975), and these results can be applicable for the excitation and growth of internal waves in the DWL, where wavenumber and frequency relations satisfy:

$$
\mathbf{k}_{1}-\mathbf{k}_{2}=\mathbf{k} \quad \text { and } \quad \omega_{1}-\omega_{2}=\omega,
$$

where $\left(\mathbf{k}_{i}, \omega_{i}\right), i=1,2$ are the wavenumbers and frequencies of surface waves, and $\mathbf{k}$ and $\omega$ are the horizontal wavenumber vector and frequency of internal wave, respectively. Note that the DWL is a strongly 

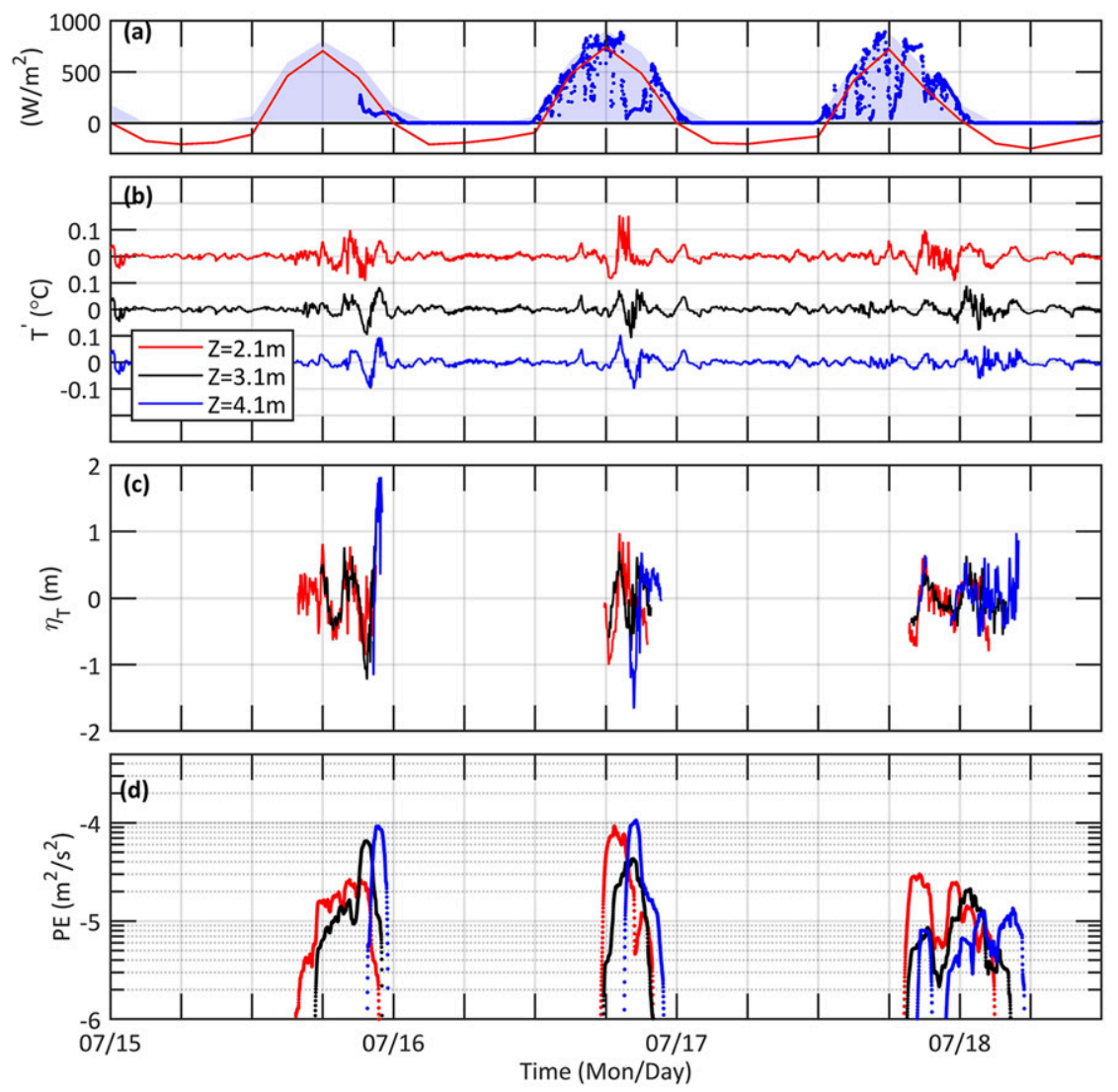

FIG. 15. Time series of (a) net heat flux (red), modeled shortwave flux (light-blue filled), and observed shortwave flux (blue dots); (b) bandpass-filtered temperature fluctuation at MS3 at depths of 2.1,3.1, and $4.1 \mathrm{~m}$; (c) internal wave displacement $\eta_{T}$; (d) the estimated perturbation potential energy $\langle\mathrm{PE}\rangle=0.5 \eta_{T}^{2} N^{2}$.

stratified, very shallow layer compared to typical openocean mixed layer depth and stratification in the thermocline. Brekhovskikh et al. (1972) derived the growth rate of internal waves for constant stratification as [Eq. (12) in Thorpe 1975]

$$
\begin{aligned}
\frac{\partial A}{\partial t}= & a_{1} k_{1} a_{2} N \pi k_{1}^{3} H^{3}\left(\frac{k}{k_{1}}\right)^{1 / 2}\left(4-\frac{k^{2}}{k_{1}^{2}}\right)^{2} \\
& \times\left[2\left(\pi^{2}+4 k_{1}^{2} H^{2}\right)\left(\pi^{2}+k^{2} H^{2}\right)^{3 / 2}\right]^{-1},
\end{aligned}
$$

where $A$ and $k$ are the amplitude and the horizontal wavenumber of the internal wave, $a_{1}$ and $a_{2}$ are the amplitudes of two surface waves, and $k_{1}$ and $k_{2}$ are the corresponding wavenumbers, $N$ is the buoyancy frequency, and $H$ is the height of water column. We can evaluate the growth rate of internal waves from (10) for surface wave measurements observed during 15-19 July (Fig. 2). For $a_{1}=a_{2}=H_{S} / 2=0.25 \mathrm{~m}, k_{1}=2 \pi / 25 \mathrm{~m}^{-1}$, $N=0.022 \mathrm{~s}^{-1}, H=h=7.8 \mathrm{~m}$, and approximating the internal wavelength, $2 \pi / k$, on the order of the unstable wavelength $\sim 60-100 \mathrm{~m}$, we find the internal wave growth, $\partial A / \partial t=2.6 \times 10^{-4} \mathrm{~m} \mathrm{~s}^{-1}$; i.e., the internal wave amplitude grows at a rate of about $1 \mathrm{~m} \mathrm{~h}^{-1}$. The growth rate of internal waves in the DWL is one order of magnitude larger than the estimate in the deep ocean reported by Thorpe (1975). This calculation suggests that internal waves gain energy rapidly from surface waves. If $\partial A / \partial t$ is scaled as $\eta_{T} / t_{A}$, where $t_{A}$ is the time scale of wave growth, and $\eta_{T}$ is the internal wave amplitude (Fig. 15), then $t_{A} \sim 1 \mathrm{~h}$ for $\eta_{T} \sim 1 \mathrm{~m}$.

\section{Summary and conclusions}

A daytime surface-layer jet and high-frequency internal waves in a thermally stratified near-surface layer were examined from observations collected on the outer Louisiana-Texas continental shelf in the Gulf of Mexico in July 2016 as part of a NRL study. The NRL deployed several moorings with multiple sensors at five sites (MS1-MS5) north of the Flower Garden Banks on the outer continental shelf of Louisiana-Texas (Fig. 1). 

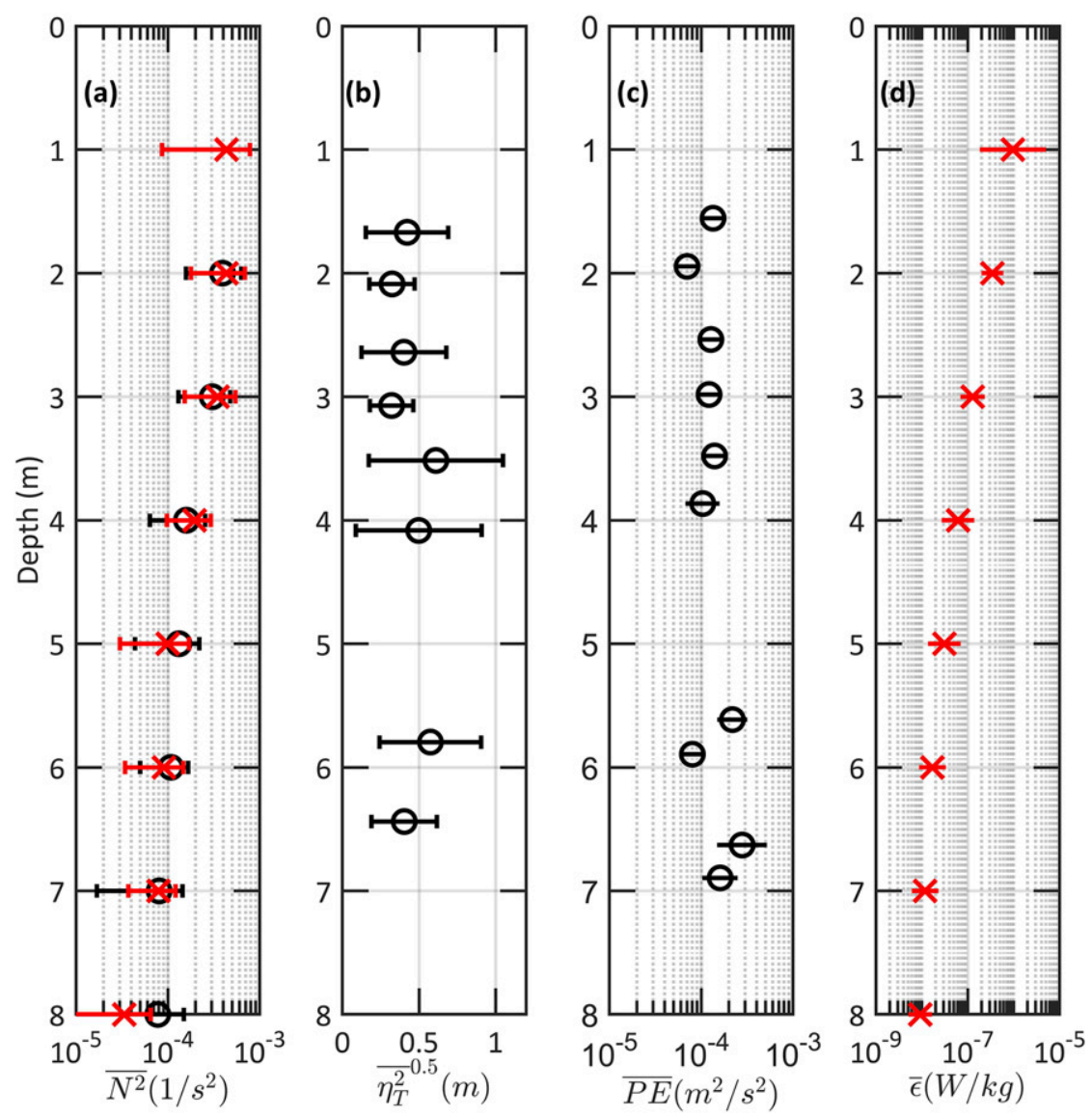

FIG. 16. (a) Time- and space-averaged vertical profile of buoyancy frequency squared $\overline{N^{2}}$. (b) Root-mean-square (rms) vertical displacements of internal waves ${\overline{\eta_{T}^{2}}}^{0.5}$. (c) Potential energy $\overline{\mathrm{PE}}$. (d) TKE dissipation rate $\bar{\varepsilon}$ associated with the internal wave band for hourly averaged data. Mean and standard deviations of $N^{2},\left[\eta^{2}\right]^{0.5}$, and PE estimated from MS1, MS2, and MS3 are marked by black circles and lines, respectively, and mean and standard deviations of $N^{2}$ and $\varepsilon$ estimated from the SLOCUM glider profiles are marked by red crosses and lines, respectively.

TKE dissipation rate $\varepsilon$ and high-vertical-resolution temperature and salinity (conductivity) profiles were collected from a MicroRider microstructure package mounted on a SLOCUM glider. We combined both moored and glider observations to examine dynamics of the DWL, and the following are the major findings.

These observations were made when the ocean surface was experiencing a weak sea breeze $\left(\sim 1-5 \mathrm{~m} \mathrm{~s}^{-1}\right)$ and daytime solar heating with a daytime average of about $400 \mathrm{~W} \mathrm{~m}^{-2}$. When winds and surface waves were weak, a thermally stratified near-surface layer formed with stratification reaching about 14 cycles per hour at 2-m depth.

The solar insolation heats and stabilizes the nearsurface layer, forming a diurnal warm layer. High values of $\varepsilon\left(\sim 10^{-6} \mathrm{~W} \mathrm{~kg}^{-1}\right)$ were found near the surface, but $\varepsilon$ was inhibited below the DWL as thermal stratification developed. Underneath the DWL, $\varepsilon$ dropped below $10^{-8} \mathrm{~W} \mathrm{~kg}^{-1}$ and turbulent eddy diffusivity became on the order of $10^{-5} \mathrm{~m}^{2} \mathrm{~s}^{-1}$. The suppressed mixing trapped the momentum imparted by wind within this layer, resulting in a surface-intensified jet in the upper $8 \mathrm{~m}$ during afternoon hours. The jet was as large as $10 \mathrm{~cm} \mathrm{~s}^{-1}$ at 2-m depth and decreased rapidly with depth. The jet rotated to the right of the wind stress and veered with depth indicating a formation of Ekman-type flow. The speed of the jet closely followed the heat content anomaly in the DWL.

During late afternoon hours, both $\varepsilon$ and $K_{D}$ in the DWL exceeded $10^{-7} \mathrm{~W} \mathrm{~kg}^{-1}$ and $10^{-3} \mathrm{~m}^{2} \mathrm{~s}^{-1}$ (Figs. 10c,d), respectively. The downward heat flux at the base of the DWL was about $200-400 \mathrm{~W} \mathrm{~m}^{-2}$, when Ri dropped below critical due to an increase in velocity shear (Fig. 8d). The nighttime cooling destroyed the strongly 
stratified DWL and thus $\varepsilon$ penetrated to deeper depths (Fig. 10c).

The vertical shear associated with the jet reduced the Richardson number below the critical value of 0.25 . Internal waves observed at 2.1-, 3.1-, and 4.1-m depths had temperature fluctuations of $\sim \pm 0.2^{\circ} \mathrm{C}$, and on average, vertical displacements varied from 0.5 to $1 \mathrm{~m}$. The internal wave field consisted of broadband high-frequency waves with periods ranging from $5 \mathrm{~min}$ to $4 \mathrm{~h}$. The perturbation potential energy associated with the wave field was $\sim 10^{-4} \mathrm{~m}^{2} \mathrm{~s}^{-2}$. These high-frequency fluctuations appeared during afternoon hours when the Ri number dropped below critical. It is suggested that the observed internal wave-like motions are a result of Kelvin-Helmholtz instabilities, since velocity and density perturbations grow when $\mathrm{Ri}<0.25$. Linear theory suggests that the wavelengths of these disturbances were about 60-100 $\mathrm{m}$.

The energy transfer through a resonant triad interaction between two surface waves and one internal wave is also a plausible mechanism within the highly stratified DWL. Internal waves can be excited or the existing wave disturbances can be amplified by gaining energy from the surface wave field through this mechanism. The growth rate of internal waves was estimated from the analytical findings of Brekhovskikh et al. (1972). The internal wave grows at a rate of about $2.6 \times 10^{-4} \mathrm{~m} \mathrm{~s}^{-1}$ or about $1 \mathrm{~m} \mathrm{~h}^{-1}$. The growth rate of internal waves in the DWL is one order of magnitude larger than in the deep-ocean estimate reported by Thorpe (1975).

The daytime jet and the high-frequency fluctuations disappeared a few hours after sunset when nighttime cooling dominated the surface heat flux. The vertical mixing resulting from dissipation of daytime internal waves can limit the rise of SST, which in turn can impact the air-sea heat fluxes. Total heat transport by sheardriven mixing, say within $4 \mathrm{~h}$ prior to nighttime, can be as large as 3-6 $\mathrm{MJ} \mathrm{m}^{-2}$, which is a significant fraction of the daytime heat buildup in the DWL. The formation of near-surface jets, internal waves, and $\mathrm{KH}$ instabilities, and the plausible energy transfer between surface waves and internal waves in the DWL as shallow as $5 \mathrm{~m}$, are a major challenge for representing detailed near-surface processes in hydrostatic model formulations.

Acknowledgments. This work was sponsored by the Office of Naval Research (ONR) in a Naval Research Laboratory (NRL) project referred to as Turbulence in the Ocean Surface Boundary Layer (TGOM). We thank Andrew Quaid and Ian Martin for their technical support. We also thank the captain, crew, and marine technicians of the R/V Pelican for their assistance. Comments given by Jim Moum, Ren-Chieh Lien, and Jody Klymak (editor) are greatly appreciated.

\section{REFERENCES}

Ball, F. K., 1964: Energy transfer between external and internal gravity waves. J. Fluid Mech., 19, 465-478, https://doi.org/ 10.1017/S0022112064001550.

Brekhovskikh, L. M., V. V. Goncharov, V. M. Kurtepov, and K. A. Naugol'nykh, 1972: Resonant excitation of internal waves by nonlinear interaction of surface waves. Izv. Akad. Nauk SSSR, Fiz. Atmos. Okeana, 8, 192-203.

Callaghan, A. H., B. Ward, and J. Vialard, 2014: Influence of surface forcing on near-surface and mixing layer turbulence in the tropical Indian Ocean. Deep-Sea Res. I, 94, 107-123, https:// doi.org/10.1016/j.dsr.2014.08.009.

Cronin, M. F., and W. S. Kessler, 2009: Near-surface shear flow in the tropical Pacific cold tongue front. J. Phys. Oceanogr., 39, 1200-1215, https://doi.org/10.1175/2008JPO4064.1.

Douglas, W., and R. Lueck, 2015: ODAS MATLAB Library technical manual, version 4.0. Rockland Scientific International Inc., https://rocklandscientific.com/support/introducing-odas-matlablibrary-4-0/.

Fairall, C. W., E. F. Bradley, J. S. Godfrey, G. A. Wick, J. B. Edson, and G. S. Young, 1996: Cool-skin and warm-layer effects on sea surface temperature. J. Geophys. Res., 101, 1295-1308, https://doi.org/10.1029/95JC03190.

Gregg, M. C., E. A. D’Asaro, J. J. Riley, and E. Kunze, 2018: Mixing efficiency in the ocean. Annu. Rev. Mar. Sci., 10, 443-473, https:// doi.org/10.1146/annurev-marine-121916-063643.

Hazel, P., 1972: Numerical studies of the stability of inviscid stratified shear flows. J. Fluid Mech., 51, 39-61, https://doi.org/ 10.1017/S0022112072001065.

Hogan, T. F., and Coauthors, 2014: The Navy Global Environmental Model. Oceanography, 27, 116-125, https://doi.org/10.5670/ oceanog.2014.73.

Jarosz, E., H. W. Wijesekera, and D. W. Wang, 2020: Observations of coherent structures in the mixed layer. 2020 Ocean Science Meeting, San Diego, CA, Amer. Geophys. Union, Abstract PS12A-02.

Jerlov, N. G., 1976: Marine Optics. 2nd ed. Elsevier Oceanography Series, Vol. 14, Elsevier, 230 pp.

Kawai, Y., and A. Wada, 2007: Diurnal sea-surface temperature variation and its impact on the atmosphere and ocean: A review. J. Oceanogr., 63, 721-744, https://doi.org/10.1007/ s10872-007-0063-0.

Kenyon, K., 1968: Wave-wave interactions of surface and internal waves. J. Mar. Res., 26, 208-231.

Kudryavtsev, V. N., and A. V. Soloviev, 1990: Slippery nearsurface layer of the ocean arising due to daytime solar heating. J. Phys. Oceanogr., 20, 617-628, https://doi.org/10.1175/ 1520-0485(1990)020<0617:SNSLOT $>2.0 . C O ; 2$.

Lueck, R. G., 2016: Calculating the rate of dissipation of turbulent kinetic energy. RSI Tech. Note TN-028, 18 pp., http:// rocklandscientific.com/?wpdmdl $=1034$.

Merckelbach, L., D. Smeed, and G. Griffiths, 2010: Vertical velocities from underwater gliders. J. Atmos. Oceanic Technol., 27, 547-563, https://doi.org/10.1175/2009JTECHO710.1.

_ A. Berger, G. Krahmann, M. Dengler, and J. R. Carpenter, 2019: A dynamic flight model for Slocum gliders and implications for turbulence microstructure measurements. J. Atmos. Oceanic Technol., 36, 281-296, https://doi.org/ 10.1175/JTECH-D-18-0168.1.

Moulin, A. J., J. N. Moum, and E. L. Shroyer, 2018: Evolution of turbulence in the diurnal warm layer. J. Phys. Oceanogr., 48, 383-396, https://doi.org/10.1175/JPO-D-17-0170.1. 
Paulson, C. A., and J. J. Simpson, 1977: Irradiance measurements in the upper ocean. J. Phys. Oceanogr., 7, 952-956, https://doi.org/ 10.1175/1520-0485(1977)007<0952:IMITUO>2.0.CO;2.

Perkins, H., F. De Strobel, and L. Gauldesi, 2000: The Barny Sentinel trawl-resistant ADCP bottom mount: Design, testing, and application. IEEE J. Oceanic Eng., 25, 430-436, https:// doi.org/10.1109/48.895350.

Price, J. F., R. A. Weller, and R. Pinkel, 1986: Diurnal cycling: Observations and model of the upper ocean response to diurnal heating, cooling, and wind mixing. J. Geophys. Res., 91, 8411-8427, https://doi.org/10.1029/JC091iC07p08411.

Smyth, W. D., J. N. Moum, L. Li, and S. A. Thorpe, 2013: Diurnal shear instability, the descent of the surface shear layer, and the deep cycle of equatorial turbulence. J. Phys. Oceanogr., 43, 2432-2455, https://doi.org/10.1175/JPO-D-13-089.1.

Soloviev, A. V., and R. Lukas, 2014: The Near-Surface Layer of the Ocean: Structure, Dynamics, and Applications. 2nd ed. Springer, $552 \mathrm{pp}$.

Sutherland, G., L. Marie, G. Reverdin, K. H. Christensen, G. Brostrom, and B. Ward, 2016: Enhanced turbulence associated with the diurnal jet in the ocean surface boundary layer. J. Phys. Oceanogr., 46, 3051-3067, https://doi.org/10.1175/JPO-D-15-0172.1.

Tennekes, H., and J. L. Lumley, 1972: A First Course in Turbulence. MIT Press, 300 pp.
Thorpe, S. A., 1966: On wave interactions in a stratified fluid. J. Fluid Mech., 24, 737-751, https://doi.org/10.1017/S002211206600096X.

_ 1971: Experiments on the stability of stratified shear flows: Miscible fluids. J. Fluid Mech., 46, 229-319, https://doi.org/ 10.1017/S0022112071000557.

- 1975: The excitation, dissipation, and interaction of internal waves in the deep ocean. J. Geophys. Res., 80, 328-338, https:// doi.org/10.1029/JC080i003p00328.

_ 1978: The near-surface mixing layer in stable heating conditions. J. Geophys. Res., 83, 2875-2885, https://doi.org/10.1029/ JC083iC06p02875.

Wenegrat, J. O., and M. J. McPhaden, 2015: Dynamics of the surface layer diurnal cycle in the equatorial Atlantic Ocean $\left(0^{\circ}\right.$, $\left.23^{\circ} \mathrm{W}\right)$. J. Geophys. Res. Oceans, 120, 563-581, https://doi.org/ 10.1002/2014JC010504.

Williams, C., R. Bachmayer, and B. deYoung, 2007: An improved model for the prediction of the performance of ocean gliders. Proc. 15th Int. Symp. on Unmanned Untethered Submersible Technology, Durham, NH, Autonomous Undersea Systems Institute, 524.

Wolk, F., R. G. Lueck, and L. C. St. Laurent, 2009: Turbulence measurements from a glider. Proc. OCEANS '09, Biloxi, MS, MTS/IEEE, 6 pp., https://doi.org/10.23919/OCEANS. 2009.5422413 